groups working on the development of industrially fabricated graphene layers that have high stiffness used as graphene based composites for optoelectronics and neural implants $[15,16]$. Graphene is the first 2D-material which consist of single atomic sheet of carbons atoms arranged in a honey comb lattice [17]. The as-discussed properties of graphene arises due to the long range $\pi$ bond conjugation which results high values of young modulus $(1 \mathrm{Tpa})^{3}$. High thermal conductivity $(5000 \mathrm{w} / \mathrm{mk})^{4}$ high carrier mobility about $\left(200,000 \mathrm{~cm}^{2} \mathrm{v}^{-1} \mathrm{~s}^{-1}\right)^{5}[18,19]$. Graphene bounds together to form graphite lattice crystals which is arranged in the form of highly ordered pyro-lytic graphite (HOPG) [20]. In the outer shell of carbon atom there are four electrons, three sigma $(\sigma)$ and one pie $(\pi)$ bond for graphene. The pie bond is $\mathrm{sp}^{2}$ hybridized which provide a strong binding force for atomic neighbors. The $\mathrm{P}_{\mathrm{z}}$ orbital as for $\pi$ bond, these results half field band improving free moving electrons demonstrate metallic characteristics [21]. Graphene material normally called zero gapes semiconductors because of the absence of any measureable band- gap in both single and double layers. The serious limitation to use graphene in electronics as switching off any device is because of lack of band gap. There is dramatic effect on the transport property of the graphene due to the addition of substrate. For traditional graphene devices silicon dioxide $\mathrm{SiO}_{2} / \mathrm{Si}$ were used as a substrate [22]. But however due to the surface roughness $\mathrm{SiO}_{2}$ could not demonstrate any impressive improvement over more initial designs [23].Therefore other substrate substances such as hexagonal boron nitrate [24] and now dichalcogenides have been tried as support [25]. On the atomic scale of graphene system, recently few observations reported particularly for suspended graphene [26]. To eliminate substrate effect, suspended graphene have been used. This suspended geometry allows exfoliating directly the impressive characteristics of graphene $[27,28]$. Combined study has shown over the past 50 years that electrons and holes at electron graphene point or (Dirac point) (Intersection point of the linear dispersion curve is called Dirac point) have zero efficient mass. Two symmetric Dirac point are being there due to two sub-lattices of graphene [29]. The cause of this zero effective mass is the energy momentum relation. These electrons/holes are called Dirac fermions or graphinos [30]. Experiments have provided that the electron mobility of graphene is ultimately high as previously reported above. Because of the zero mass, graphene electron act like photons. Charge carrier have the ability to cover sub-micrometer distances, without dispersion and this phenomena is called ballistic transport [31]. The strength of graphene is permanent from the beginning. In 2007, atomic force microscopy (AFM) were performed on graphene single-layer that were suspended over $\mathrm{SiO}_{2}$ cavities, these experiment showed that graphene had very much strong and uniform young modulus of $0.5 \mathrm{Tpa}$ [32]. In the optical characteristics, graphene has also capability to absorb rather large $2.3 \%$ of the white light is a thorough characteristic of graphene. Recently it was proved that the absorption of white light is the cause of fine design constant. Due to these fascinating properties, saturated absorption takes place when once optical intensity approaches a certain critical point [33]. Graphene can be functionalized which result various substances such as graphene oxide or fluorinated graphene [34]. At present, overwhelming attention has started to the electronic and framework features of carbon-based materials as well as graphene are now hottest topic in condensed matter physics. This is not only due to the outstanding properties of graphene regarding its mechanical stability, thermal conductivity, and 2-dimensional layers but also unusual electronic properties such as Dirac-particles with linear dispersion transport energy gap and simple absorption coefficient of light [12]. So, it could have a unique practical application due to these unique properties. Graphene monolayers have been fabricated by exfoliating graphene flakes from the bulk graphite and depositing them on $\mathrm{SiO}_{2} / \mathrm{Si}$ substrate.

To address some of the TMDCs, One of the most studied and widely used layered transition metal dichalcogenides (LTMDCs) is molybdenum disulfide $\left(\mathrm{MoS}_{2}\right)$. It has wonderful electrical, optical, chemical and mechanical properties which makes it a suitable candidate to be used as a catalyst in hydrogen evolution reaction (HER) as active material or transport material in solar cells photo catalyst, as electrodes in lithium batteries. Similar to other LTMDCs bulk $\mathrm{MoS}_{2}$ is indirect band gap of magnitude $1.2 \mathrm{eV}$. When exfoliated to a monolayer the value of band gape changes to $1.9 \mathrm{eV}$. These effects make $\mathrm{MoS}_{2}$ a strong candidate in the field of 2D devices [35]. $2 \mathrm{H}-\mathrm{WS}_{2}$ is a semiconductor having indirect band gap of $1.3 \mathrm{eV}$. After exfoliation of monolayer $\mathrm{WS}_{2}$ indirect band gap become direct band gap. These monolayers of $\mathrm{WS}_{2}$ are connected by Vander Waal interaction which turn makes it a thin 2D layer. The $2 \mathrm{H}$ - $\mathrm{WS}_{2}$ is n-type semiconductor having charge carrier density of $1014 \mathrm{~cm}^{-3}$ at room temperature. The crystal size of $\mathrm{WS}_{2}$ is hexagonal having lattice parameters of $a=b=0.315 \mathrm{~cm}, c=1.22, a=\beta=90$ and $Y=120$, which is characterized by Raman spectroscopy and hall measurement [36]. Molybdenum diselenide is a unique type of transition metal dichalcogenides (TMDCs) which has been special in the mind of researcher due to its extraordinary applications in photoluminescence devices, lubricants, solar cells, field effect transistors and super-capacitors [37]. In the family of TMDCs $\mathrm{NiSe}_{2}$ is one of the materials that can be studied for the production of control over nanostructure. Because of the extraordinary morphologies the nickel selenide has been expected for the application 
of energy research, such as storage, electrochemistry and catalytic activity in the hydrogen evolution reaction (HER) [38]. $\mathrm{NbS}_{2}$ is a $2 \mathrm{D}$ conducting material belongs to the family of TMDCs. It can be said that to made ohmic relation with 2D semiconductors materials due to its high work function and Vander Waal interface which make it suitable for semiconductor. Regardless of the importance of $\mathrm{NbS}_{2}$ as an electrode, the previous methods of production could not control the thickness, size and consistency of niobium disulfide $\left(\mathrm{NbS}_{2}\right)$. $\mathrm{NbS}_{2}$ can be used as electrode material in super-capacitors. $\mathrm{Tas}_{2}$ is one of the TMDC which shows attractive combination of valuable structure, mechanical, chemical and electronic properties. Its electronic properties and structure are very useful for high power applications such as micromechanical system, superconductors and super-capacitors.

\section{Graphene-based composites}

Materials created by mixing two or more components with various characteristics to produce a final product with extraordinary characteristics are called composite materials. As was mentioned before, graphene has countless of new attributions, any amount of which could be used to produce outstanding composites. Composites with superb qualities can be made by the presence of graphene which ultimately improve the strength and conductivity of bulk material [39]. Graphene can be attached to metals, polymers and ceramics to manufacture heat and pressure resistant composites. Graphene composites have a variety of applications and a great deal of research is underway to produce unique and interesting materials. The endless uses of graphene-composites in photo-catalytic process are worthy of being light, versatile and best electrical conductors. However, in the following section authors are going to discuss graphene based transition metal oxides composites.

\subsection{Transition metal oxides-graphene composites}

There are many plans to produce composites of graphenemetal. The un-usual structural and excellent mechanical properties of transition metal graphene composites are related to the strengthening mechanism of graphene, and excellent interaction between the metal matrix and the graphene. With traditional metallurgical process to get graphene contain metal matrix composites, due to the big difference in density between graphene Nanoplatelets and metal matrix, there are numerous issues [40]. The huge interest in this area is growing because of the countless applications of transition metal- graphene composites. Following are some different types of graphene reinforced-transition metal composites. Recently, the composite of graphene and magnesium reinforced were fabricated by the combination of ball-milling and hot pressed sintering techniques [41-43]. The impact of graphene on the microstructure and mechanical characteristics was investigated by scanning electron microscope (SEM) and using energy dispersive spectroscopy (EDS) to explore composite crystal structure [44]. The mechanical characteristics of the composite also enhanced with the addition of graphene owing to standardized graphene production. Magnesium and its alloys have wide range of uses in the area of aero-space and automotive industry due to their low mass density and outstanding damping capacity, but due to low strength and ductility its uses are limited [45]. Therefore by the addition of graphene all these properties were trigger [46]. Chen et al. [47] have extracted the Mg composite strengthened with graphene Nano-platelets by combining ultrasonic liquid state processing and solid state stirring and obtained amazing improved properties. Furthermore Magnesium produced metal matrix composite enhanced by the use of graphene Nano-platelets (GNPs) by powder metallurgy $[43,48,49]$ Rashad et al. SEM images for graphene- magnesium composite indicate that graphene Nano-particles are equally distributed in the magnesium matrix and dark black areas reveals oxidation during sintering process. The mechanical strength of magnesium increased from 57.5 to 68.5 when combined with graphene. The resulted tensile strength increased to 197 and $238 \mathrm{MPa}$ (Fig. 1).

The first studied graphene-based composite among metal-graphene composites is graphene-reinforced aluminum matrix composite. Bartolucci et al. asserted in 2011 that graphene platelet composites and Al powder were generated by ball milling, warm iso-static pressing and extrusion [51]. The development of Al carbide described the inferior mechanical characteristics of the composite during the consolidation and subsequent heating and extrusion phase. In 2012, Wang et al. recorded aluminum composite strengthened with graphene Nano-layers using peel powder metallurgy [52]. The impact on tensile strength of aluminum composite was only $0.3 \mathrm{wt} \% \mathrm{GNS}$ is $249 \mathrm{MPa}$. It was $62 \%$ better than the standard Al matrix. The composite and corresponding $\mathrm{Al}$ tensile characteristics are shown in Fig. 2a, b. Also graphene reinforced Al was fabricated by mixing graphene-Cu powder into melted Aluminum [53]. The picture of the Al composite with graphene-cu through scanning electron microscopy is shown in Fig. 2. In addition, the composite graphene-Al (6061) was generated by ball milling, by semi-solid thermal compaction [53].

Copper-graphene composite were synthesized by jagannadham in 2011 [54]. It was found appropriate by dropping the graphene oxide (GO) on the Cu surface 

pictures; a unalloyed Magnesium, b magnesium $/ 0.3$ wt $\%$ GNPs composite with clear picture [50]
Fig. 1 SEM broken surface
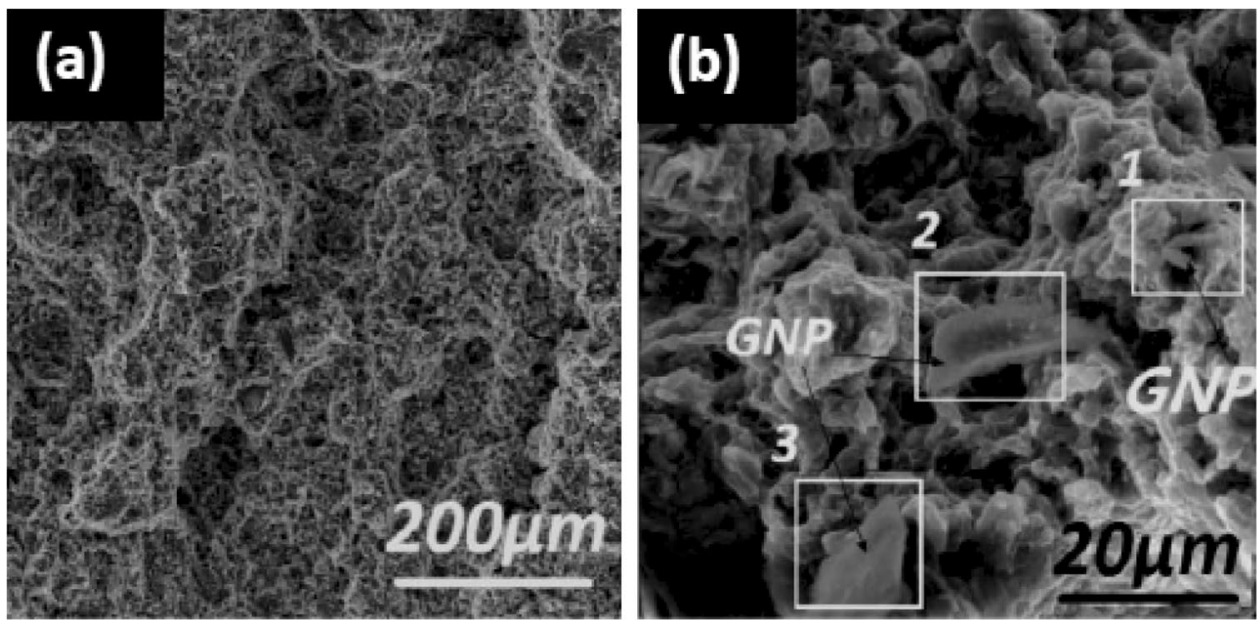

Fig. 2 a 0.3 wt \% GNS/Al composite tensile characteristics and the respective flaky Al sample; b 0.3 wt $\%$ GNS/AI composite fracture structure; the inset indicates the GNS drawn out [52]
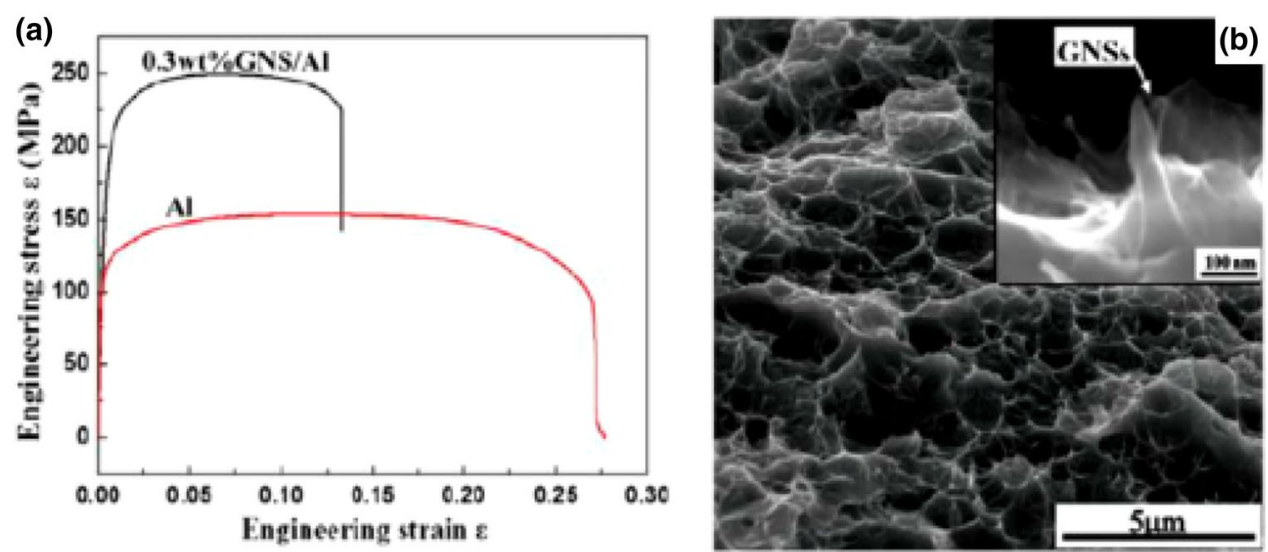

and then drying a thin sheet of Cu was placed on top of the graphene oxide by laser physical vapor deposition. Figure 3 shows the SEM picture of graphene on the $\mathrm{Cu}$ substrate. It is clear from Fig. 3 that graphene is highly agglomerated, which decrease the mechanical properties. After reinforcement of graphene the hardness of aluminum composite increased by $40 \%$ as compared to pure Al. Jagannadham subsequently revealed in 2011 that graphene-reinforced Cu matrix composite was also produced by $\mathrm{CuSO}_{4}$ electrochemical co-deposition and graphene oxide solution [55]. A paper on the preparing of Cu-graphene composite was released in 2012 [56], in which graphene was firstly produced on the layer of the micron sized Cu-powder by chemical vapor deposition. The as-produced materials were then compressed by cold rolling reported by kaltosva et al. to obtain bulk composite. After the structural study of the composite it was seen that the strength is increased by $39 \%$ as compared to unreinforced $\mathrm{Cu}$. For the preparation of graphene enhanced Cu matrix by Hwang et al. in 2013, molecular level blending technique and spark plasma sintering (SPS) process were used [57].
SEM image of the Cu-graphene sheet can be shown in the Fig. 4. The grey areas are copper and the dark regions are graphene. It is predicted that the cross-plane thermal conductivity of the copper was affected due to low thermal conductivity of graphene perpendicular to $a b$ plane.

Nickel is an important industrial and also carbon-stable material. The nickel graphene composites was firstly studied by Hu et al. in 2012 [59]. It was made from graphene oxide sheets using $\mathrm{Ni}$-plating in $\mathrm{NiSO}_{4}$ solution without electricity. The microstructure of $\mathrm{Ni}$-graphene composites is shown in Fig. 5. It was believed that the as-prepared composite could be used as catalysts owing to the big particular region, the permeable shape and constant absorption of Ni particles on the film surface of the graphene. Kumar et al. revealed $\mathrm{Ni}$ graphene composite coating on stainless steel plates in 2013 [60]. They used electrodeposition method to fabricate it. The author's research indicates that the coating material graphene increases the nucleation rate and stops the development of crystals. The electro-deposition of $0.12 \mathrm{wt} \%$ was also reported by kuang et al. [61]. Where the composite was manufactured using nickel sulphamate solution blended with graphene.

\section{SN Applied Sciences}



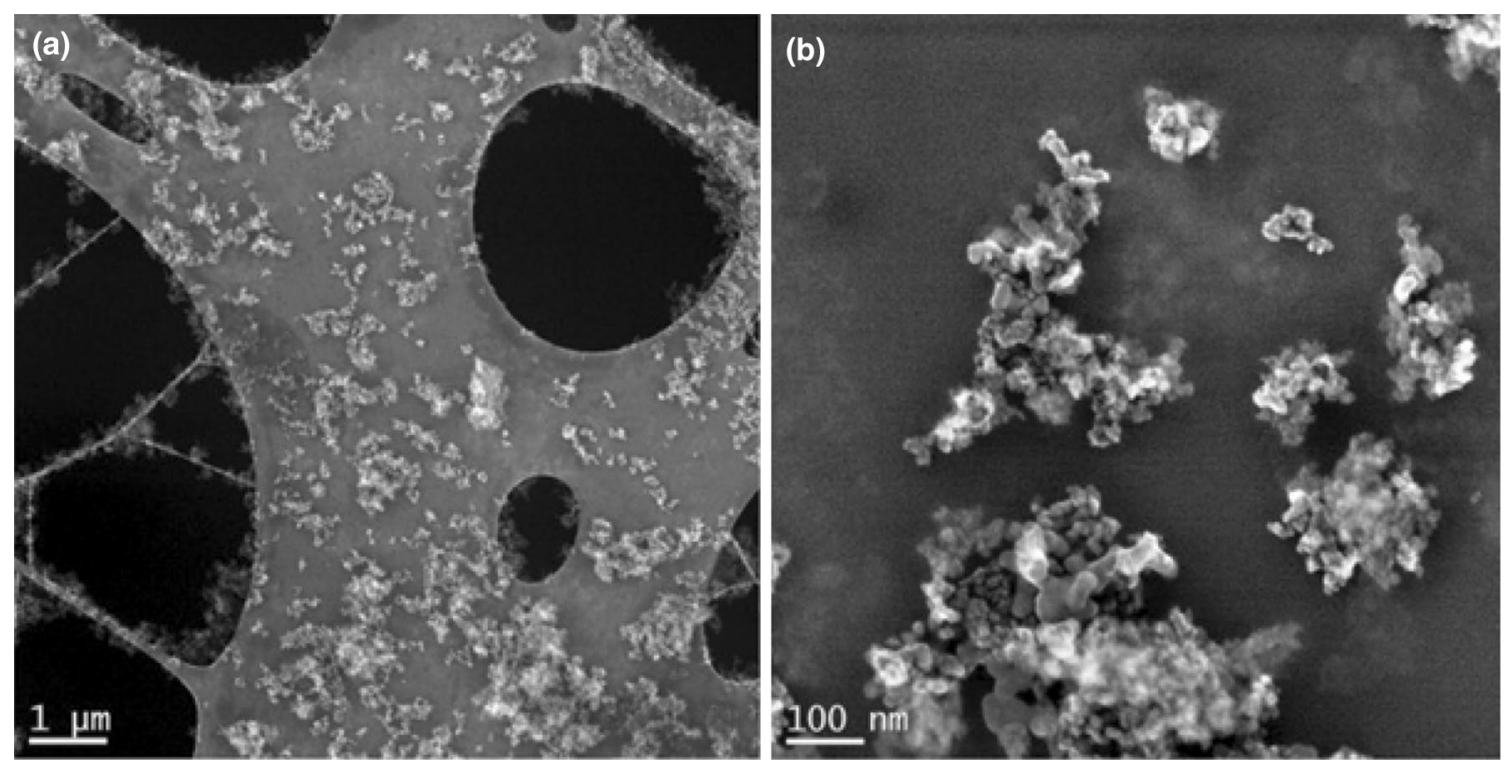

Fig. 3 SEM picture of Al composite by mixing with graphene-Cu [53]

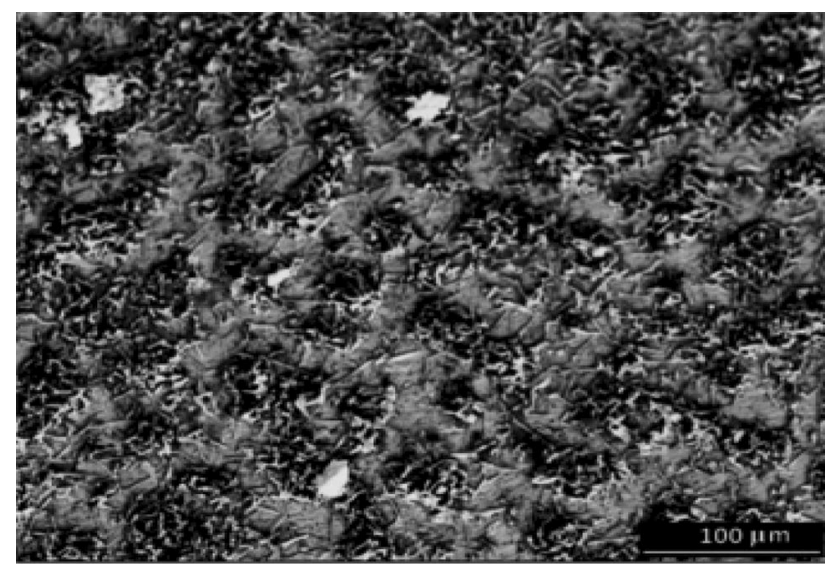

Fig. 4 SEM picture of the Cu-graphene sheets. [58]
After the procedure, the composite's thermal conductivity was 15 percent higher than ordinary $\mathrm{Ni}$. The composite strength was 4 times greater than mere material. Ren et al. [60] reported similar work with different mechanical outcomes. The composite in the Kuang technique has 6.85 GPa hardness and $252.76 \mathrm{GPa}$ elastic modulus, while the findings were 4.6 and $240 \mathrm{GPa}$ respectively in Ren's job.

So far there are very less reports and studies on the iron-graphene composites. However graphene oxide-iron composites was reported by Lin et al. in 2014 [64]. The laser sintering process was employed for the production. The hardness of the iron-graphene composites was found to be $93.5 \%$ of the pure material. The interfacial structures and strengthening mechanism of the composites were also investigated as shown in Fig. 6 . The documented

(b)

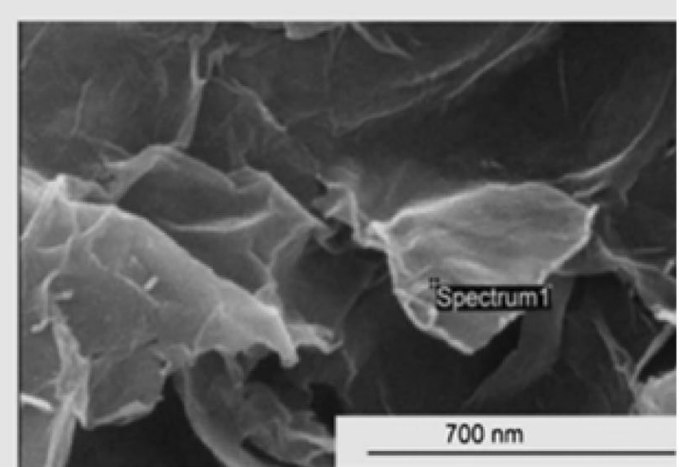

Fig. 5 a Synthesized films of Ni/graphene [62]. b Dried Ni/graphene sheets at $383 \mathrm{~K}$ for 12 h [63] 

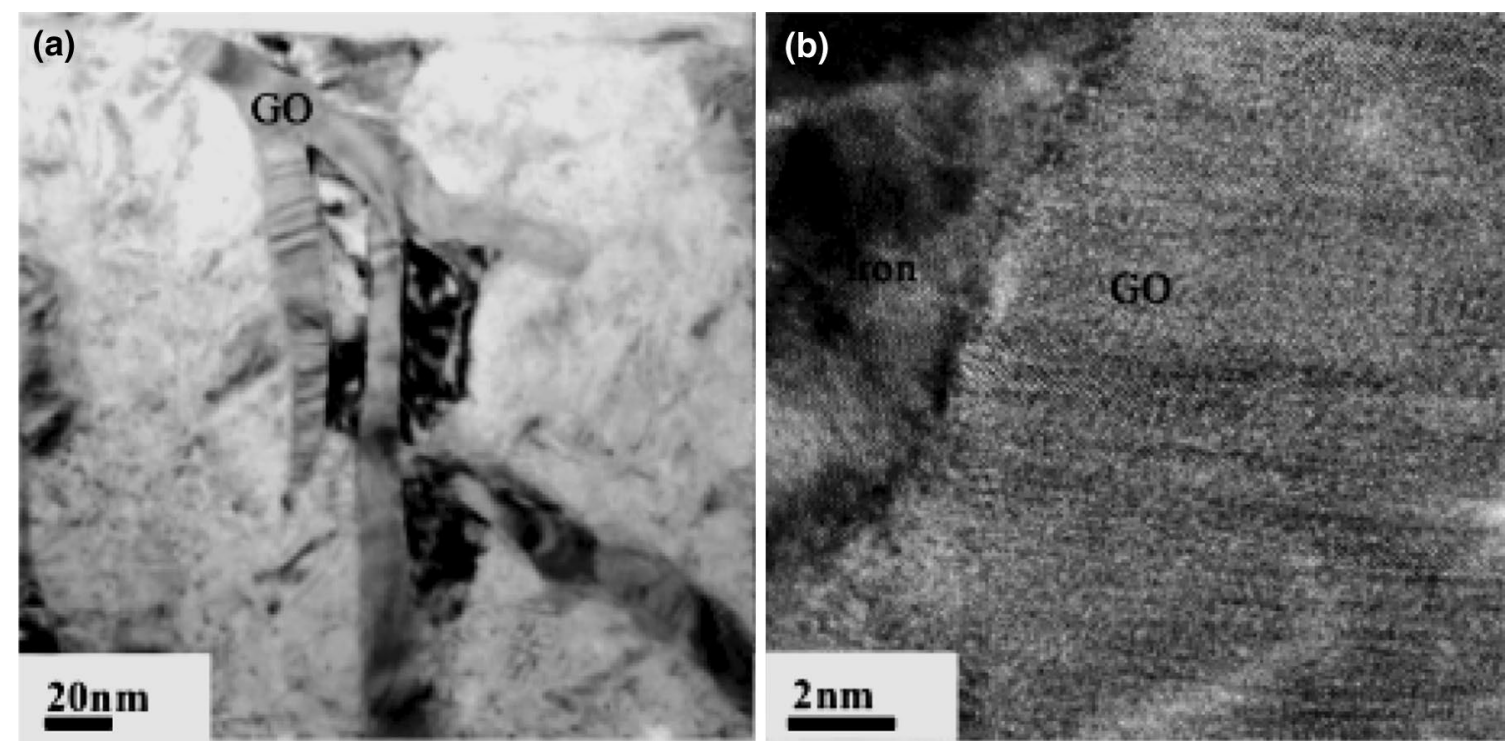

Fig. 6 a Cross sectional TEM images of GOs; b HRTEM of Fe (iron) combination and GO [64]

laser coating micro-hardness of $2 \mathrm{wt} \% \mathrm{GO}$ composite was $600 \mathrm{HV}$, which is 93.5 percent higher than the basic material. The transmission electron microscopy (TEM) image of $\mathrm{GO}$ and HRTEM picture of its composite with iron (Fe) are shown in Fig. 6. However there are various studies on the transition metal-graphene composites. These composites can be used as catalysts, photo-catalysts, materials for battery storage and conversion, biosensors and many more. Some of the common graphene based composites are Fe-Ni graphene composites [65], Ag-graphene composites [66], Au-graphene composites [67-69], Pt-graphene composites [70], Pb-graphene composites [71], Cd-graphene composites [72] and so on.

Tungsten oxide is an electrochemically sustainable metal oxide of type $\mathrm{n}$ with implementations in different sectors. Because of their superior effective applications in energy storage devices, gas detectors, photo-catalyst, field-emission devices, and electro-chromic, nanostructured tungsten oxide $\left(\mathrm{WO}_{3}\right)$ products have gained growing interest [73-75]. Due to their significant surface area and low charge movement resistance, nanostructured tungsten oxides $\left(\mathrm{WO}_{3}\right)$ as electrode components are anticipated to exhibit improved electrochemical efficiency $[76,77]$. Among some of the different nanostructures, onedimensional (1D) components such as nanowires and nanotubes are particularly appealing in terms of dimensionality and shape, considered to be exogenous constituents that can deliver new and outstanding characteristics. $\mathrm{WO}_{3}$ has been investigated to be an interesting electrode component for super-capacitor and other energy storage devices because of the interpolation/de-interpolation of protons and electrons into oxide [78]. But its applications are limited for pseudo-capacitors due to low conductivity and less rate of performance [79]. It is researched that to enhance the performance and features of $\mathrm{WO}_{3}$ is to make hybrid material of $\mathrm{WO}_{3}$ with various carbon fibers, conducting polymers and reduced graphene oxides [80]. However a lot of work has been carried out on $\mathrm{WO}_{3}$ as positive electrode material than negative. To fabricate composite of $\mathrm{WO}_{3}$ and graphene various methods were deployed, but the most reliable technique was hydrothermal method $[81,82]$. Transmission electron microscopy and field emission scanning electron microscopy were used to study the morphologies and microstructure mechanism of the sample. Various particles of metal oxides like $\mathrm{WO}_{3}$ and $\mathrm{Ce}-\mathrm{O}_{\mathrm{x}}$ (cerium oxide) were placed on the surface of every graphene layer. The specific capacitance of the device was improved when the metal oxides were placed on the surface of graphene. The high specific capacities $377.5 \mathrm{mFg}^{-1}$, $368.75 \mathrm{Fg}^{-1}, 331 \mathrm{Fg}^{-1}$ and $325 \mathrm{Fg}^{-1}$ at a scan rate of $2 \mathrm{mVs}^{-1}$ were obtained from deposition of $\mathrm{Ce}-\mathrm{O}_{\mathrm{x}}$ and $\mathrm{WO}_{3}$ for $\mathrm{W}_{2}$, $\mathrm{W}_{4}, \mathrm{~W}_{3}$ and $\mathrm{W}_{1}$ respectively. Both the Nano-composites showed advantageous electrochemical redox properties and reactivity of ions. The following table shows various values of specific capacitance when the fabrication methods, crystal structure and morphologies of the sample are different (Table 1).

Titanium di-oxide has been considered to be one of the best compounds for super-capacitor electrodes. The reasons that make it excellent option are best chemical stability, low fabrication cost, non-toxic in nature, huge availability and large surface area, which gives a capacity value of $235.6 \mathrm{Fg}^{-1}$ at current density of $0.5 \mathrm{Ag}^{-1}$ [91, 92]. This capacitance value, nevertheless, should only be

\section{SN Applied Sciences


Table 1 Relation of $\mathrm{WO}_{3}$ made super-capacitor's electrochemical characteristics and its various crystal configuration

\begin{tabular}{|c|c|c|c|c|c|c|}
\hline Sample & Morphology & Crystal structures & $\begin{array}{l}\text { Fabrication tech- } \\
\text { niques }\end{array}$ & Specific capacitance & Cycling stability & Ref \\
\hline $\mathrm{WO}_{3}$ & Microspheres & Hexagonal & Hydrothermal & $\begin{array}{l}538 \mathrm{Fg}^{-1} \text { at scan rate } \\
\text { of } 5 \mathrm{mVs}^{-1}\end{array}$ & $\begin{array}{l}\text { 85\% capacitance } \\
\text { retention after } \\
2000 \text { cycles }\end{array}$ & [84] \\
\hline $\mathrm{h}-\mathrm{WO}_{3}$ & $\begin{array}{l}\text { Aligned nano pillar } \\
\text { bundles }\end{array}$ & Hexagonal & Hydrothermal & $\begin{array}{l}488.78 \mathrm{Fg}^{-1} \text { at scan } \\
\text { rate } 0.5 \mathrm{mVs}^{-1}\end{array}$ & $\begin{array}{c}\text { Retained almost } \\
84.75 \% \text { within } \\
10,000 \text { cycles }\end{array}$ & {$[76]$} \\
\hline $\mathrm{WO}_{3}$ & Nano fibers & Hexagonal & Hydrothermal & $\begin{array}{l}536.72 \mathrm{~F} \mathrm{~g}^{-1} \text { at scan } \\
\text { rate of } 10 \mathrm{Ag}^{-1}\end{array}$ & $\begin{array}{l}\text { Retained } 92.3 \% \text { of } \\
\text { initial capacitance } \\
\text { after } 2000 \text { cycles }\end{array}$ & {$[85]$} \\
\hline $\mathrm{H}$-WO3. $\mathrm{n} \mathrm{H}_{2} \mathrm{O}$ & Nano rod & Hexagonal & Hydrothermal & $\begin{array}{l}342 \mathrm{Fg}^{-1} \text { at scan rate } \\
\text { of } 5 \mathrm{mVs}^{-1}\end{array}$ & $\mathrm{~N} / \mathrm{A}$ & {$[86]$} \\
\hline $\mathrm{WO}_{3}-\mathrm{WO}_{3} \cdot 0.5 \mathrm{H}_{2} \mathrm{O}$ & $\begin{array}{l}\text { Disordered nano } \\
\text { rods }\end{array}$ & Hexagonal and cubic & $\begin{array}{l}\text { Microwave-assisted } \\
\text { hydrothermal }\end{array}$ & $\begin{array}{l}44 \mathrm{Fg}^{-1} \text { at current } \\
\text { density of } 0.5 \mathrm{Ag}^{-1}\end{array}$ & $\mathrm{~N} / \mathrm{A}$ & {$[87]$} \\
\hline $\mathrm{m}-\mathrm{WO}_{3}-\mathrm{x}$ & Meso-porous & Cubic & Template-assisted & $\begin{array}{l}302 \mathrm{Fg}^{-1} \text { at current } \\
\text { density of } 10 \mathrm{Ag}^{-1}\end{array}$ & $\mathrm{~N} / \mathrm{A}$ & {$[88]$} \\
\hline $\mathrm{WO}_{3} \cdot 2 \mathrm{H}_{2} \mathrm{O}$ & Amorphous & Amorphous & $\begin{array}{l}\text { Microwave irradia- } \\
\text { tion }\end{array}$ & $\begin{array}{l}391 \mathrm{~F} \mathrm{~g}^{-1} \text { at current } \\
\text { density of } 0.5 \mathrm{Ag}^{-1}\end{array}$ & $\begin{array}{l}82 \% \text { retention after } \\
10,000 \text { cycle }\end{array}$ & [89] \\
\hline $\mathrm{WO}_{3}$ & Irregular rods & Monoclinic & Hydrothermal & $\begin{array}{r}436 \mathrm{Fg}^{-1} \text { at current } \\
\text { density of } 1 \mathrm{Ag}^{-1}\end{array}$ & $\begin{array}{l}\text { 93\% of initial capaci- } \\
\text { tance after } 5000 \\
\text { cycles remained }\end{array}$ & {$[90]$} \\
\hline
\end{tabular}

achieved at an ideal size below $10 \mathrm{~nm}$ with ultrathin sheets or Nano-scaled particles $[93,94]$. Due to their extreme specific capacity and maximum power rate sensitivity with different microstructures, $\mathrm{TiO}_{2}$ has been researched for use in wide scale energy storage. A preferred 3D structure with adequate active frameworks to resolve the low ion diffusion coefficient $\left(10^{-13}-10^{-17} \mathrm{~cm}^{2} / \mathrm{s}\right)$ [92] and heavy electrical resistance is crucial to realizing the value of super-capacitors based on $\mathrm{TiO}_{2}$. The production of titanium dioxide nanotube arrays $[95,96]$ or nanoparticles [97] are therefore a usual process to assisting ion transport and enhancing electrolyte-active surface interaction. Also practical applications of $\mathrm{TiO}_{2}$ are less because of low volumetric density and less conductivity. In order to enhance the electrical conductivity of $\mathrm{TiO}_{2}$ coating or insertion of conducting polymer or carbon decoration has been carried out $[98,99]$. Due to this composition process the electrical behavior was far improved. However to make further enhancement the coating should be done with porous conductive material and also deposition techniques to carried out the process. Recently graphene has been considered one of the best conductive and porous materials that can be used as substrate to coat $\mathrm{TiO}_{2}$. Graphene's adaptable mesopore and macrospore structures enable the surface to be covered by Nano scale components yet at the same time maintaining conduction networks for electron transport. To fabricate graphene Nano-composites various methods have been used like hydrothermal, sol-gel and electroplating. Neither of these method can completely use the elevated graphene surface area or regulate the accumulation of metal oxide in the nanometer scheme. However $\mathrm{TiO}_{2}$-graphene has shown some improvement but size controlling remains a challenge [100]. In contrast atomic layer deposition (ALD) in considered one of the efficient approach to carried out the mechanism [101]. The $\mathrm{TiO}_{2}-\mathrm{G}$ composites established using ALD exhibit unique electrochemical reliability with good maintenance capacity at a rapid scan rate. The manufactured $\mathrm{TiO}_{2} \mathrm{Nano}^{-m e m-}$ brane was used for high capacitance of super-capacitor. The experimental result had showed a specific capacity of $2332 \mathrm{Fg}^{-1}$ at $1 \mathrm{Ag}^{-1}$ with $100 \mathrm{TiO}_{2}$ ALD cycles and energy density of $81 \mathrm{whkg}^{-1}$. As the ALD cycles increase, the capacity decreases. In contrast to previous studies on $\mathrm{TiO}_{2}$ there is a great improvement in specific capacity of $\mathrm{TiO}_{2}$. The capacitance has increased $400 \%$ with composition of $\mathrm{TiO}_{2}$ as compared to graphene. Different studies were carried out by various researchers. Reddy et al. extracted a specific capacity of $160 \mathrm{Fg}^{-1}$ by hydrothermal method for $\mathrm{TiO}_{2} /$ MWCNTs (multiwall carbon nanotubes) Nano-crystalline composite with 99\% detention [102]. $\mathrm{TiO}_{2}$ prepared by in situ microwave irradiation method shows elevated specific capacitance value of $585 \mathrm{Fg}^{-1}$ at a uniform current density of $1 \mathrm{Ag}^{-1}$ [103]. The SEM, TEM and HRTEM images of the product are shown in the following Fig. 7 with ALD cycles.

$\mathrm{SnO}_{2}$, because of its unique characteristics, has received a lot of attention as a transparent semiconductor. Tin oxide $\left(\mathrm{SnO}_{2}\right)$ can also be used as electrode material in supercapacitor. Tin oxide with various structural morphologies containing 1D nan-rods, 2D Nano-layers and 3D shapes 


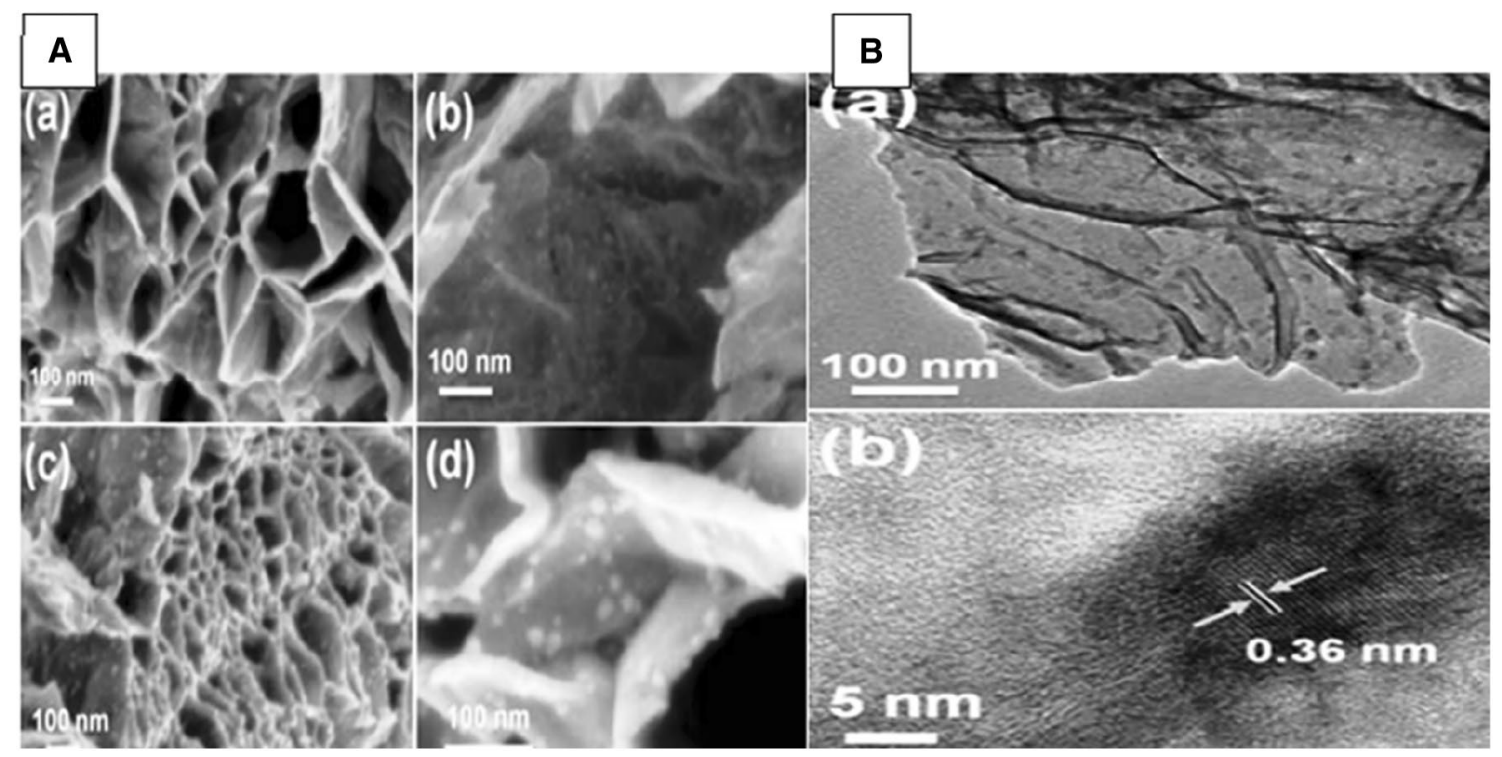

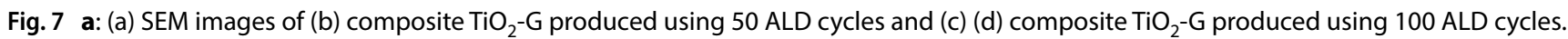
b: (a) TEM and (b) $\mathrm{TiO}_{2}-\mathrm{G}$ hybrid material HRTEM image produced using 100 ALD cycles [104]

can display speedy charge transportation, which made them unique candidate for fabrication of electrodes [105]. Tin oxide has fascinating properties like high power density and low cost which expands its applications in various areas for instance lithium ion batteries, solar cells, sensors and super-capacitors [106-109]. However poor charge transportation and less electrical conductivity makes its uses limited [110]. To improve these characteristics we need to create composite material of $\mathrm{SnO}_{2}$ with graphene. Since graphene has large surface area and good electrical conductivity $[111,112]$. To fabricate such type of hybrid electrode material various techniques have been deployed like hydrothermal synthesis, one step synthesis and pulse microwave deposition method etc. which has different consequences in specific capacitance. Li et al. accumulated $\mathrm{SnO}_{2}$ on graphene sheets in the presence of hydrochloric acid and urea by reducing graphite oxide with $\mathrm{SnCl}_{2}$. The fabricated product has good capacitive properties. Kim et al. revealed a simple and direct strategy for the production of graphene- $\mathrm{SnO}_{2}$ composites with elevated lithium storage capacity by incorporating $\mathrm{NH}_{4} \mathrm{OH}$ and hydrazine to $\mathrm{RGO}$ and oxidizing tin-particles with $\mathrm{HCl}$ [105]. Field emission scanning electron microscopy (FESEM) was carried out to study the morphology of as-produced composite. Figure 8 shows the structural behavior of $\mathrm{SnO}_{2}$ and $\mathrm{SnO}_{2}$ Nano-composite. Furthermore, findings of electrochemical coupling spectroscopy (ECS), cyclic voltammetry (CV) and galvanostatic load discharge affirm unique electrochemical characteristics of the super-capacitor graphene$\mathrm{SnO}_{2}$ Nano-composite. The formulated $\mathrm{FLG} / \mathrm{SnO}_{2}$ Nanocomposite's basic capacitance showed outstanding strong capacitance capacitive efficiency $\left(365 \mathrm{Fg}^{-1}\right)$, outstanding cyclic appearance relative to Pure $\mathrm{SnO}_{2}$ Nano-particles [113].

Copper oxide $(\mathrm{Cu}-\mathrm{O})$ is one of the low price intercalation materials in contrast to other noble metals or metal oxide Nano-structures. Because of its fascinating features like huge availability, low price, best capacitive properties and less toxicity to environment expand its applications to many areas like, active anode material, heterogeneous catalyst, superconductors and sensors $[105,114]$. Graphene-Cu-O Nano-composite has been fabricated through hydrothermal method assisted by ammonium solution by many researchers for application of supercapacitors. To study the surface morphology of the asproduced product, high resolution transmission electron microscopy (HR-TEM) and scanning electron microscopy (SEM) were carried out. Furthermore, reduced graphene oxide-copper sulfide was also studied as electrode material because of its elevated theoretical capacity and best electro-conductivity. RGO/CuS composite shows high capacitance values of $946 \mathrm{Fg}^{-1}$ at $10 \mathrm{Mvs}^{-1}$ and $906 \mathrm{Fg}^{-1}$ at $1 \mathrm{Ag}^{-1}$, respectively. The cycling stability was also super it maintains $89 \%$ after 5000 cycles at current density of $5 \mathrm{Ag}^{-1}$ [115]. A three-dimensional graphene oxide aerogel/copper oxide (3DGOA/CuO) cylindrical composite substance has been effectively manufactured as a super-capacitor electrode material using a comfortable one-step self-assembly hydrothermal procedure. The as prepared product exhibit improved specific capacity of $211 \mathrm{Fg}^{-1}$ at current density of $1 \mathrm{Ag}^{-1}$ [116]. Also the high specific capacity was obtained from Nano-composite 


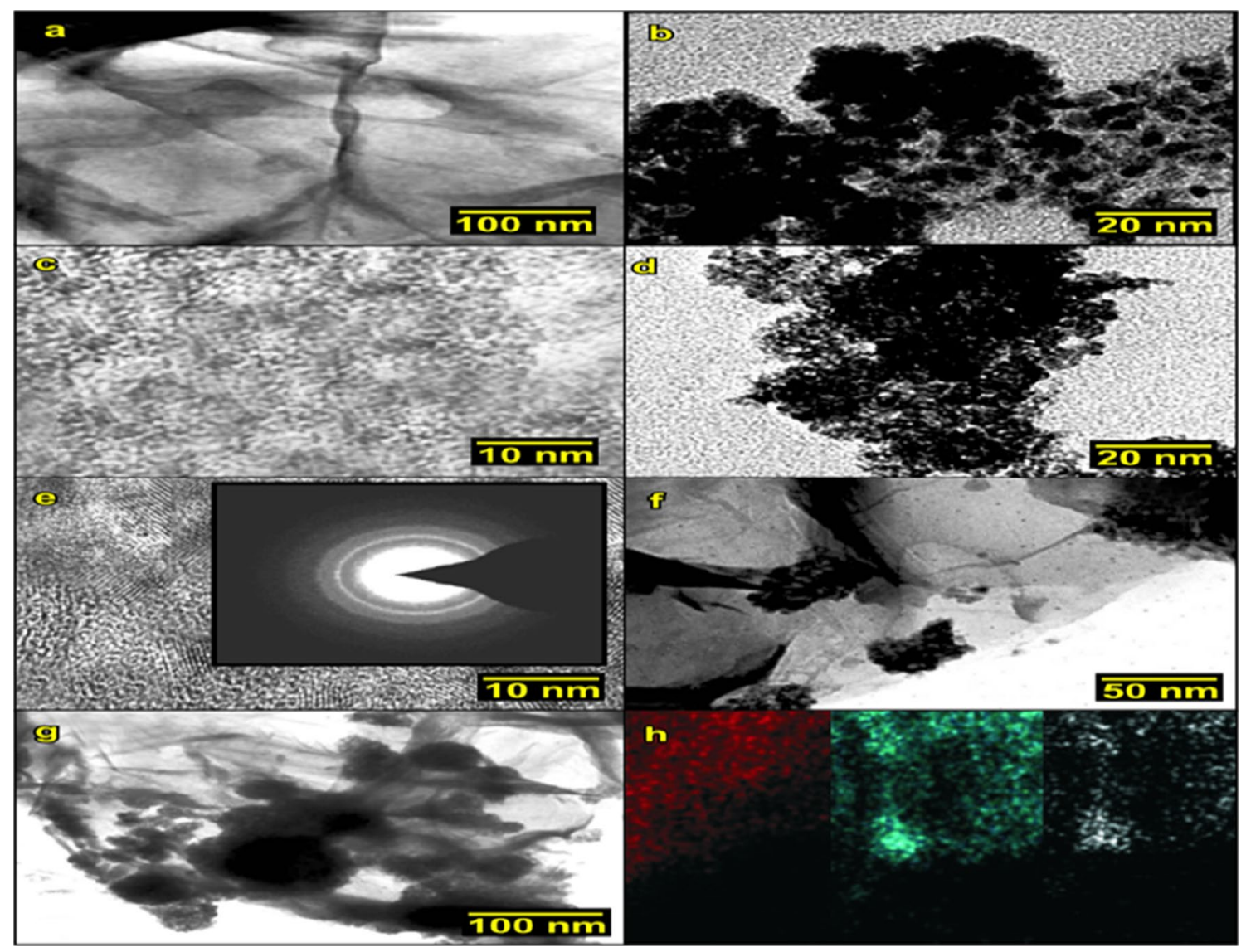

Fig. 8 a, b TEM image of G-SnO 2 c-g TEM and HR-TEM images of $\mathrm{SnO}_{2} / \mathrm{G}$ Nano-composite and $\mathbf{f}$ Elemental structure of $\mathrm{SnO}_{2} / \mathrm{G} \mathrm{Nano-com-}$ posite [105]

foam layer of copper oxide and graphene is $238.3 \mathrm{Fg}^{-1}$ [117]. The surface morphology was examined by scanning electron microscopy (SEM) as shown in figure. Moreover when nickel-copper foam is combined with graphene oxide it shows an elevated capacitance of $1320.2 \mathrm{Fg}^{-1}$ at a discharge rate of $2 \mathrm{Ag}^{-1}$ and energy density of $30.01 \mathrm{whkg}^{-1}$ at power density of $10.2 \mathrm{kwkg}^{-1}$ [118] (Figs. 9, 10).

Three dimensional decreased graphene oxide Nanosheet containing iron oxide nanoparticle $\left(\mathrm{Fe}_{3} \mathrm{O}_{4} \mathrm{NPs}\right.$ ) hybrid ( $3 \mathrm{D} \mathrm{Fe}_{3} \mathrm{O}_{4} / \mathrm{RGO}$ ) produced by one-pot microwave approach. Figure 11 shows scanning electron microscopy pictures of $\mathrm{Fe}_{3} \mathrm{O}_{4} / \mathrm{RGO}$ nanostructure and different magnification rate [119].

By using galvanostatic charge/discharge method and cyclic voltammetry, the calculated the specific capacitance of $3 \mathrm{D}$ hybrid $\mathrm{Fe}_{3} \mathrm{O}_{4}$ is $455 \mathrm{Fg}^{-1}$ and $317 \mathrm{Fg}^{-1}$ at a scanning rate of and $27 \mathrm{mVs}^{-1}$ respectively [119], which is better than all previous graphene- $\mathrm{Fe}_{3} \mathrm{O}_{4}$ based supercapacitor electrode [120-122]. The 3D hybrid illustrates great cycling stability with a retention ratio of $91.4 \%$ from around 190 cycles to 9600 cycles.
A stand-alone hybrid film combining Nano-flakes of graphene and zinc oxide used as electrode substrate was prepared by through an easy self-assembly filtration and heat reduction techniques. Thy hybrid film can be used effectively for super-capacitors as binder-free and self -supported electrode material [123].

The maximum capacity of prepared zinc oxide is almost 167.2 $\mathrm{Fg}^{-1}$ at a tracking rate of $5 \mathrm{mVs}^{-1}$, while RGO-ZnO prepared by hydrothermal method have a specific capacitance of $156 \mathrm{Fg}^{-1}$ at a scan rate of $5 \mathrm{mVs}^{-1}$. The graphene$\mathrm{ZnO}$ electrode exhibit excellent cycling ability, maintenance of the initial capacity over $90 \%$ after 2000 cycles [123]. The electrochemical impedance spectroscopy analysis shows low electrical resistance and improving ion diffusion capacity [123]. Figure $11 \mathrm{a}, \mathrm{b}$ shows the reduced graphene oxide and zinc oxide films and specific capacity as a function of tracking rate respectively [123].

$\mathrm{CV}$ of the hydrous $\mathrm{RuO}_{2} / \mathrm{G}$ composite with different Ru loads with a scanning rate of $10 \mathrm{mVs}^{-1}$ shows that the integrated area, corresponding to the specific capacity, increases up to $55.8 \%$ as shown in Fig. 12a. The specific capacitance of $\mathrm{RuO}_{2} / \mathrm{G}$ shows in Fig. 12b, corresponding 
(a)
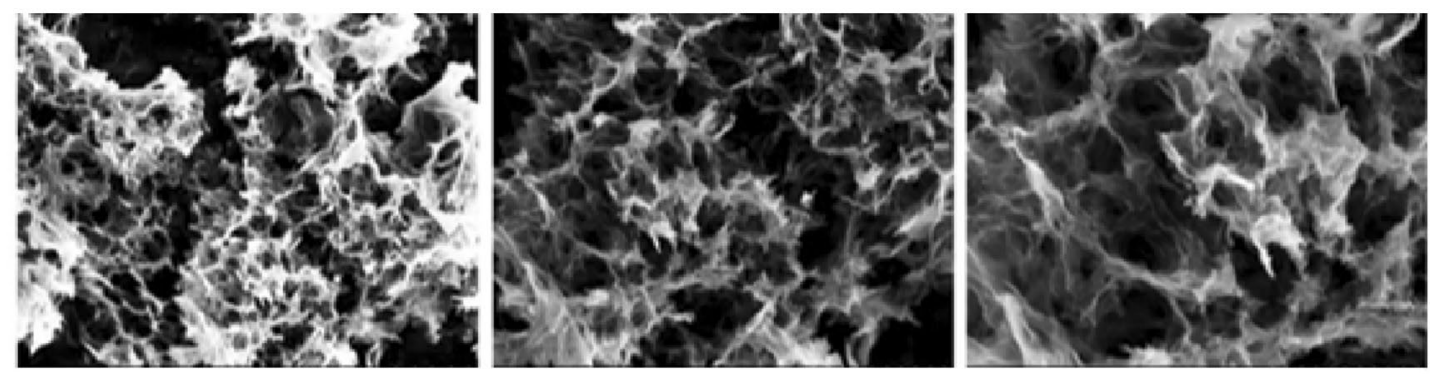

(b)
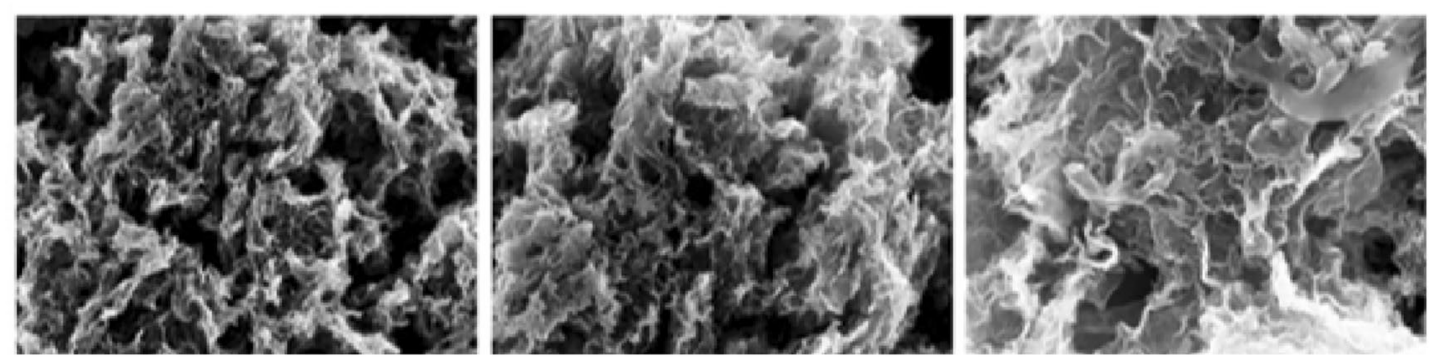

Fig. 9 Scanning electron microscopy (SEM) images of GOA (graphene oxide aerogel) $\mathbf{a}$ and 3DCuO/GOA $\mathbf{b}$ at less and elevated magnification [116]
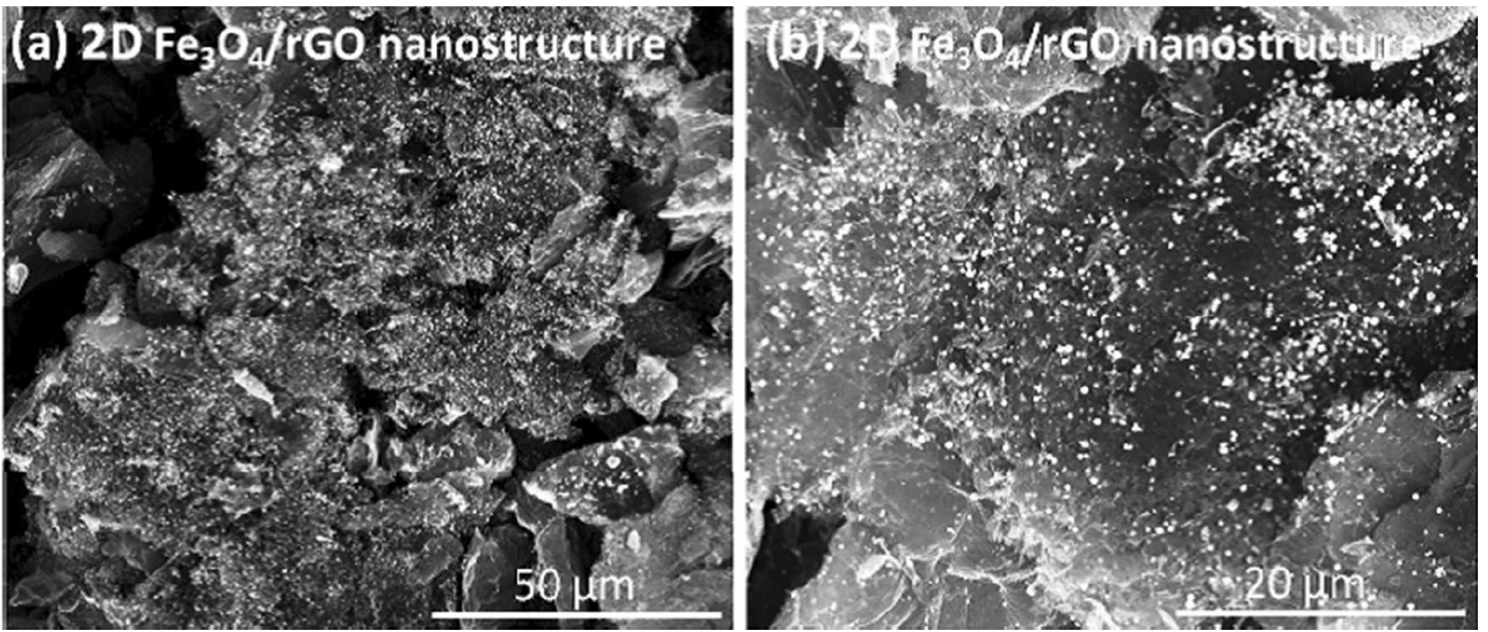

Fig. 10 a and $\mathbf{b}$ Shows SEM picture of $\mathrm{RGO} / \mathrm{Fe}_{3} \mathrm{O}_{4}$ at magnification rate of $50 \mathrm{~mm}$ and $20 \mathrm{~mm}$ respectively [119]

to different current densities ranging from 0.1 to $20 \mathrm{Ag}^{-1}$. Figure $12 \mathrm{c}$ shows that the capacitance retention of $80.5 \%$ of $\mathrm{RuO}_{2} / \mathrm{G}$ composite with $44.6 \mathrm{wt} \%$ of $\mathrm{Ru}$, even at a high current rate of almost $20 \mathrm{Ag}^{-1}$. The volumetric capacitance of $1485 \mathrm{Fg}^{-1}$ at a current density of $0.1 \mathrm{Ag}^{-1}$ is shown in Fig. 12d [124].

Figure 13 shows the ragone plot which demonstrates outstanding performance of $\mathrm{RuO}_{2} / \mathrm{G}$ composite. A maximum volumetric energy density of $50.6 \mathrm{WhL}^{-1}$ can be achieved for the $\mathrm{RuO}_{2} / \mathrm{G}$ composite with a $44.6 \mathrm{wt} \% \mathrm{Ru}$ charge at a power density of $32.9 \mathrm{WL}^{-1}$ based on the amount of active material [124].
$\mathrm{V}_{2} \mathrm{O}_{5}$ Nano-rods prepared by sol-gel technique, while graphene oxide is prepared by Hummer's method [125, 126]. The prepared $\mathrm{V}_{2} \mathrm{O}_{5}$ and $\mathrm{GO}$ powders is taken in $1: 1$ ratio, the $\mathrm{V}_{2} \mathrm{O}_{5}$ dissolved in distilled water then $\mathrm{GO}$ is added. The mixed solution is stirred at $80^{\circ} \mathrm{C}$ until the solution fully evaporated [127], the obtain Nano composite is $\mathrm{RGO} / \mathrm{V}_{2} \mathrm{O}_{5}$. The specific capacitance of RGO/ $\mathrm{V}_{2} \mathrm{O}_{5}$ is 290 and $186 \mathrm{Fg}^{-1}$ at a scanning rate of 5 and $10 \mathrm{Ag}^{-1}$ respectively which is higher than that of bare $\mathrm{V}_{2} \mathrm{O}_{5}$ which is 144 and $93 \mathrm{Fg}^{-1}$ at same tracking rate [127]. The ragone plot for bare $\mathrm{V}_{2} \mathrm{O}_{5}$ and $\mathrm{RGO} / \mathrm{V}_{2} \mathrm{O}_{5}$ is shown in Fig. 14. 
(a)

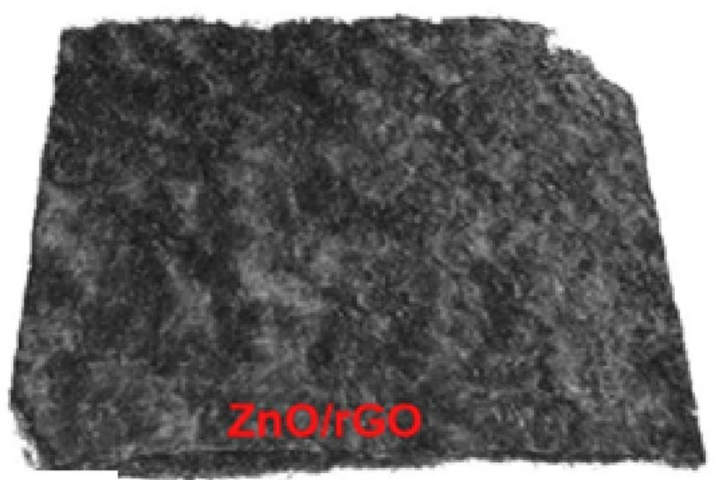

(b)

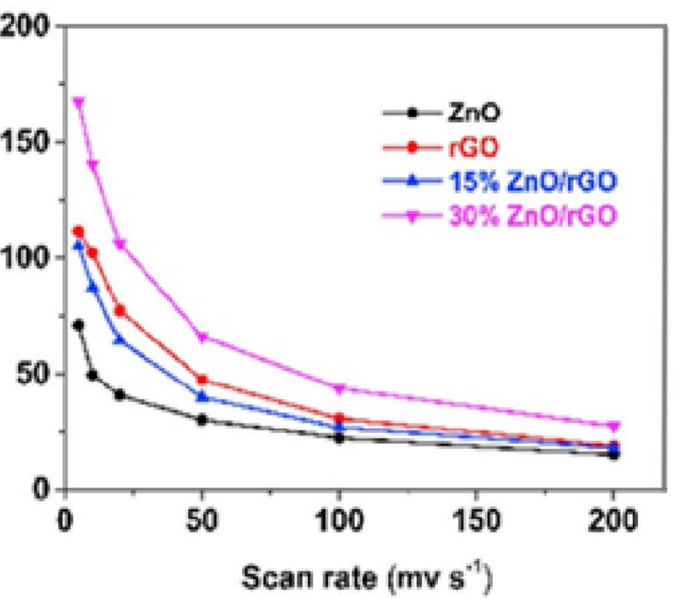

Fig. 11 a It shows RGO/ZnO film. b Specific capacitance at different scanning rate [123]

(a)

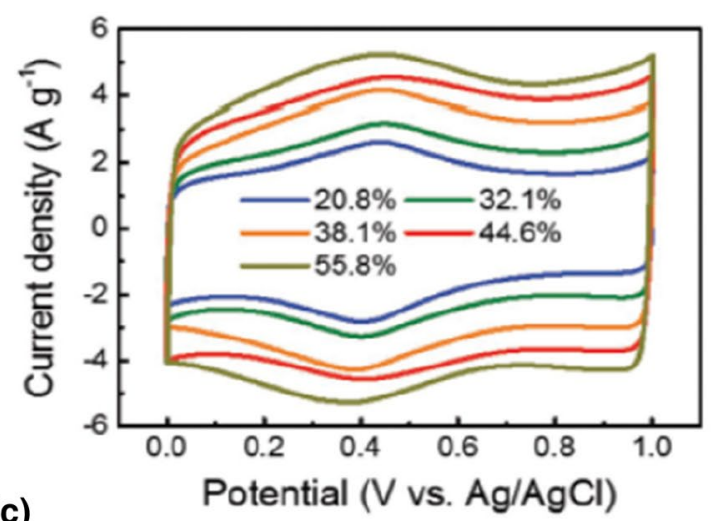

(c)

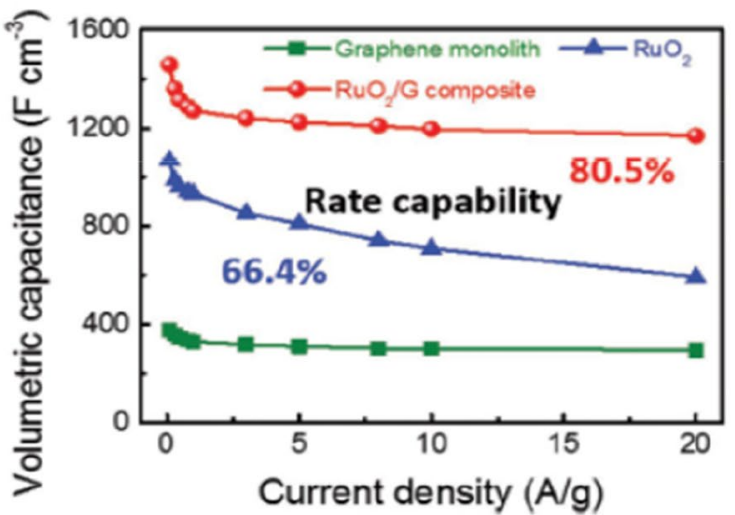

(b)

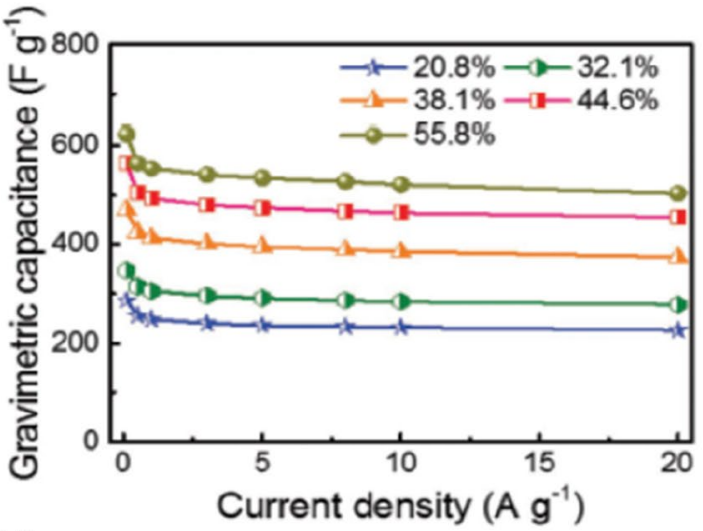

(d)

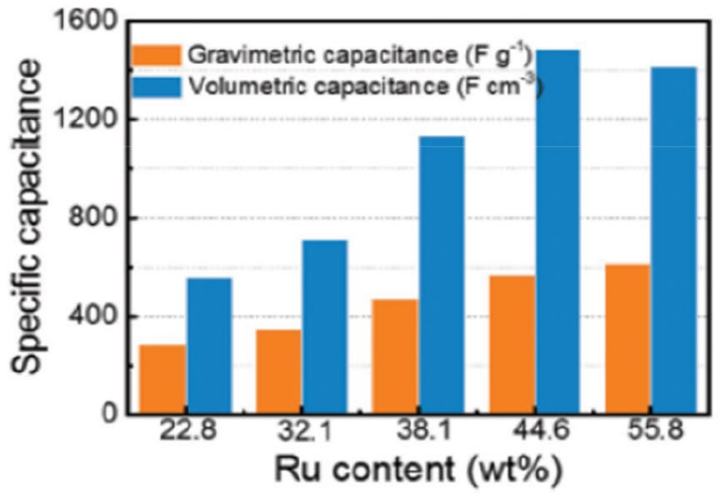

Fig. 12 a CV curves at scan rate of $10 \mathrm{~m}$ versus b Gravimetric capacitance of composites with different Ru loading at various current densities. c Shows the volumetric of composites. d Gravimetric and volumetric capacitance [124]

To sum up the graphene based composites on the basis of improved features various kinds of reinforcements with distinct characteristics are accessible for use in metal matrix Nano-composites (MMNCs) particularly, based on aluminum, copper and magnesium. Based on the metal matrix, manufacturing method and required properties, the choice of reinforcement is executed. The primary necessary reinforcement features based on 


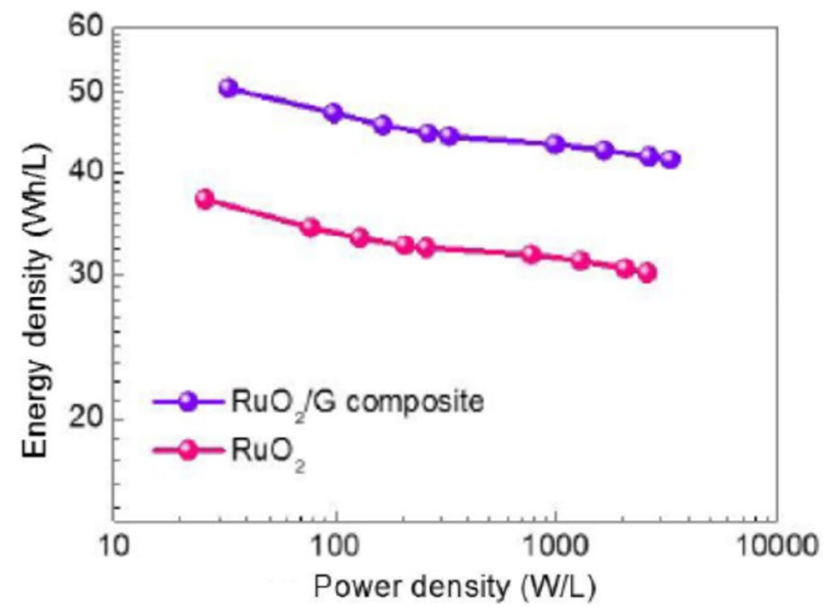

Fig. 13 Hydrous $\mathrm{RuO}_{2} / \mathrm{G}$ \& pure $\mathrm{RuO}_{2} / \mathrm{G}$ ragaone plot [124]

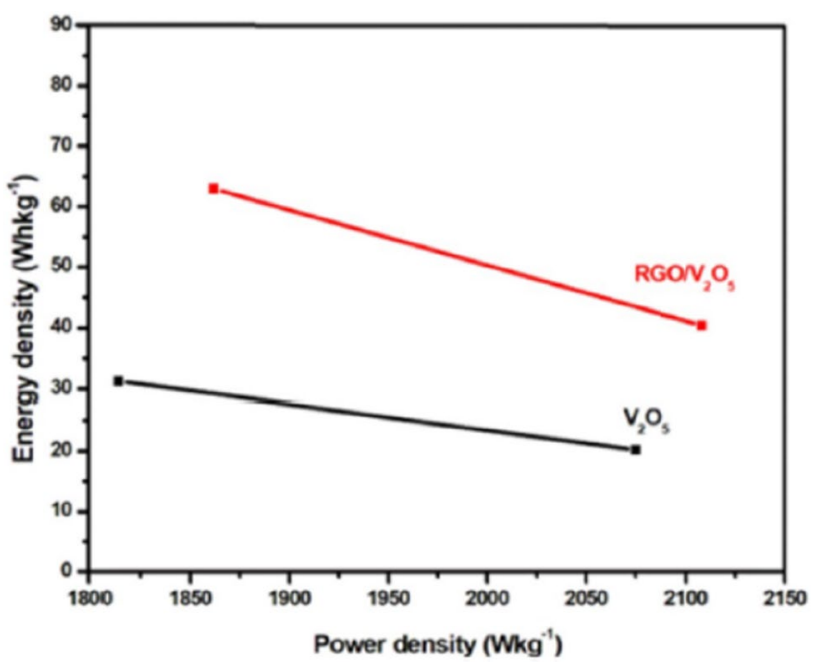

Fig. 14 It demonstrate the ragone plot for $\mathrm{V}_{2} \mathrm{O}_{5}$ and $\mathrm{RGO} / \mathrm{V}_{2} \mathrm{O}_{5}$ [127]

composite application may be a mixture of some of the following characteristics, relatively low specific gravity, elevated Young's modulus, high strength, chemical and mechanical matrix compatibility, high heat and electrical conductivity, and low thermal expansion coefficient [128]. As mentioned previously, magnesium is, in theory, rather light and its modulus is somewhat small, while its power is not sufficiently high. In addition, its thermal expansion coefficient is quite large, while it is electrical and heat characteristics are medium. Similarly aluminum has same limitations therefore, in order to create a new aluminum-based composite with greater mechanical and physical characteristics and a desirable low heat expansion coefficient, high strength and high modulus, at least adequate strengthening is essential. In order to extend the applications of aluminum, copper, magnesium and Nickel in the electronic packaging industry and meet the criteria in this field, it is necessary to use very high thermal conductive reinforcements with a low coefficient of thermal expansion. Also gold-Nano-composites have stunning properties when added to graphene, Au-graphene composites are low cost material used in super-capacitor electrodes. It displayed stable capacity values of 100 and $500 \mathrm{Fg}^{-1}$ for the chemically synthesized Nano-composite electrodes and using ionizing radiation, which stayed continuous over $5-500 \mathrm{mVs}^{-1}$ potential scan speed. Furthermore, the reinforcement chosen should be sufficiently light to maintain the composite as light as possible. Under these conditions, it is possible to use carbon-based reinforcement materials as reinforcements to create fresh composite materials with superior mechanical, physical and thermal characteristics.

In the spectrum of above discussion we are going to use graphene based materials in the fabrication of supercapacitor electrodes and how the graphene materials enhanced the storage capability of super-capacitors.

A super-capacitor has very high value of capacitance more than other capacitors [129]. The storage ability of super-capacitors is 10 to 100 times more than electrolytic capacitors. It can get and release charges in much high rate than batteries. Super-capacitors are also called supercap, ultra-capacitors, gold-cap or electrostatic double layer capacitors (EDLCs) [130]. There are two main differences between super-capacitors and ordinary capacitors. The area of super-capacitors plates is very large and the separation between the plates is very small. The sheets of super-capacitors made of metal covered with absorbent materials such as powder, activated charcoal, which eventually raises the surface area to increase the load [131]. There is no dielectric between the plates of super-capacitors, however, both sheets are wetted in an electrolyte and segregated by a very slender carbon insulator, paper or plastics as shown in Fig. 15. As the area of the plate increases and the distance between the plates decreases, the capacitance of the capacitors increases. Specific capacitance of super-capacitors is heavily influenced by carbon electrodes with a significant surface space available to electrolyte ions, porous carbon materials such as activated carbon [132], carbide-derived carbons [133, 134], arranged meso-porous carbons [135, 136], carbon aerogels and carbon nanotubes have been investigated as large-surface electrodes [137]. Graphene-based materials are desirable because of their elevated theoretical volume ratio ( $2630 \mathrm{~m}^{2} \mathrm{~g}^{-1}$ and electrical conductivity) [138] as electrode materials for super-capacitors. Numerous graphene-based materials with unique chemical structures and morphologies such as chemical-modified graphene [139], microwave enhanced graphite oxide 
Fig. 15 Internal structure and working principle of supercapacitors [142]

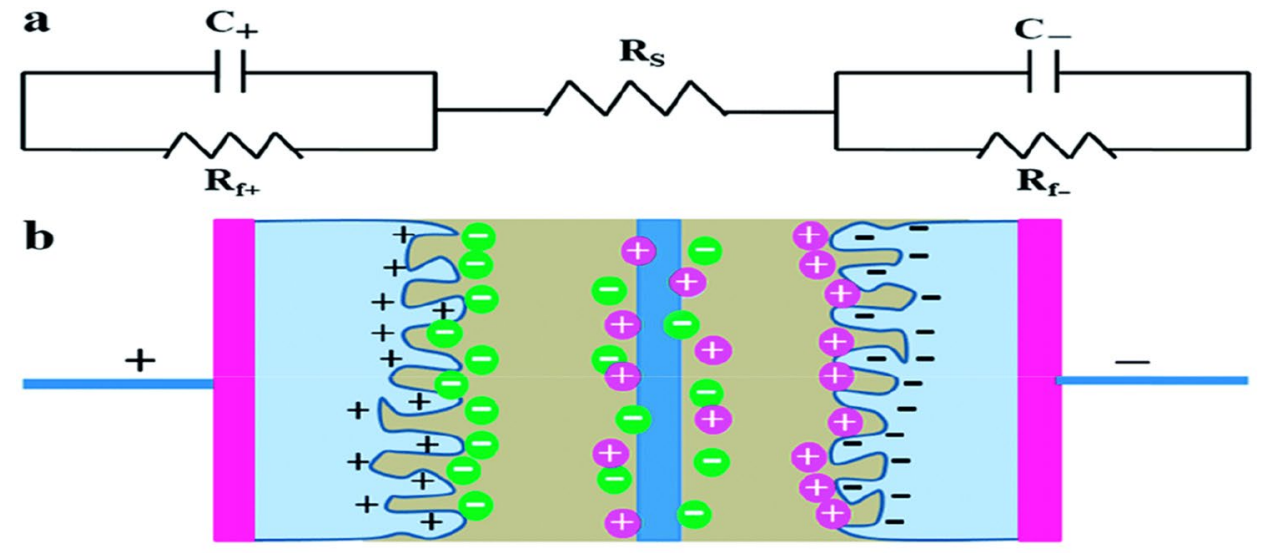

c

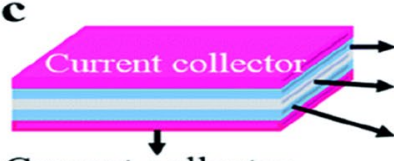

Electrode material

Separator and electrolyte

Electrode material

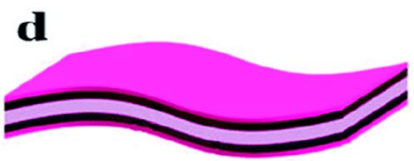

Current collector

(MEGO) [140] and curved graphene [141] were studied as super-capacitor's electrode components. This large portion of microwave broadened graphite oxide (a-MBGO) of micro- and meso-porous that provides a big and available region to accommodate charges and thus increases the specific capacity of organic and ionic liquid electrolytes to obtain a remarkably elevated spectroscopy density. The first super-capacitors were created in the first of 1950s using activated charcoal as labels, but over time progress in material science resulted to the growth of much more efficient carbon nanotubes plates, barium titanate, aerogels and graphene. The internal structure and mechanism of super-capacitor is shown in the following Fig. 15.

The energy density for $\mathrm{V}_{2} \mathrm{O}_{5}$ is $31.25 \mathrm{Whkg}^{-1}$ and $20.18 \mathrm{Whkg}^{-1}$ and that for RGP/V $\mathrm{N}_{5}$ is $62.93 \mathrm{Whkg}^{-1}$ and $40.36 \mathrm{Whkg}^{-1}$ respectively at a scan rate of 5 and $10 \mathrm{Ag}^{-1}$ [127]. The calculated power density for $\mathrm{V}_{2} \mathrm{O}_{5} 1.814 \mathrm{kWkg}^{-1}$ and $2.075 \mathrm{kWkg}^{-1}$ and that for $\mathrm{RGO} / \mathrm{V}_{2} \mathrm{O}_{5}$ is $1.862 \mathrm{kWkg}^{-1}$ and $2.201 \mathrm{kWkg}^{-1}[126,127]$.

To date, numerous materials such as new carbon fabrics [143], conductive polymers, hybrid metals oxides have been deployed as super-capacitors electrodes [144-146]. Carbon was generally used in its various forms as supercapacitors of electrode components, due to High specific capacity and elevated production density $[147,148]$. Although permeable carbon components have a big specific surface area, their operation in super-capacitors with high energy density is limited by the low conductivity of porous carbon materials. Since 1997, carbon nanotubes (CNTs) have been manufactured for super-capacitors with exceptional electrical conductivity and elevated surface fields. However, the anticipated performance was not met by CNT-based super-capacitors; the measured contact resistance between the electrode and the current collector is probably one reason. Graphene is a notable carbon material with the ability to use electrochemical energy storage devices owing to its outstanding chemical stability, high electrical conductivity and strong surface features. Graphene has recently been suggested as a sustainable material for super-capacitor application [149], and two graphene super-capacitor implementation studies with a specific capacity of $135 \mathrm{Fg}^{-1}$ in aqueous electrolyte and $117 \mathrm{Fg}^{-1}$ in aqueous $\mathrm{H}_{2} \mathrm{SO}_{4}[139,150]$ based on a multi-sheeted graphene matrix have been recorded. The effective size of graphene parts as condenser electrode parts does not depend on the distribution of solid-state pores, unlike conventional high-surface products [139] which is distinct from the present super-capacitors made of activated carbon and carbon nanotube [146, 151, 152]. Definitely, the effective surface area of graphene materials should be highly dependent on the substrates, i.e. one or several layers of graphene with less aggregation should be presumed to have more effective surface area and therefore better supercapacitor outcomes. So in this work we are going to review graphene and different other materials for the electrodes of super-capacitor. The reason that researchers use graphene or graphene based materials for electrodes because they have high surface area and light weight. Recently, there are many records of super-capacitors based on graphene to enhance specific capacity using different electrolytes such as potassium hydroxide, organic electrolyte and ionic liquids [153]. Chenguang et al. indicated high power density graphene-based super-capacitor. This was accomplished with twisted morphology for a large surface graphene. Moreover, their estimated discharge capacitance value $\left(154.1 \mathrm{Fg}^{-1}\right)$ at $1 \mathrm{Ag}^{-1}$ is still comparatively small and the release period at $76.3 \mathrm{Whkg}^{-1}$ is $120 \mathrm{~s}$. Afterward, Yanwu 
et al. [154] examined graphene super-capacitors, capacitance characteristics with the same ionic liquid. In addition, pseudo-capacitors with metal oxide and polymer graphene composites have been observed by many study organizations with enhanced efficiency involving faradic reactions [155]. But the strength and mechanical stability of the electrode during electrochemical responses in such pseudo-capacitors is low, resulting development in the polymer-based electrode area that needs to be resolved before real-time operations occur. Composites of metal oxide graphene used to enhance capacity contain $\mathrm{Mg}-\mathrm{O}$, $\mathrm{Fe}_{3} \mathrm{O}_{4}, \mathrm{MnO}_{2}$, and cobalt oxide [156-160]. Graphene can be used in many different designs, i.e. zero dimensional materials or points, odd-dimensional strand or yarns, 2D films and 3D graphene materials.

Chemical graphite exfoliation into GO can manufacture graphene dots and droplets, followed tunable reduction in GO (with reducing agent such as hydrazine hydrate). The associated chunks of graphene are easily solubilized and by the preceding decrease the rGO becomes hydrophobic, affecting more water development or aqueous circumstances. GO, Just from the other hand, there is a special amphiphile with negatively charged hydrophilic edges and hydrophobic cell membrane [161]. This distinctive feature makes it possible for $\mathrm{GO}$ to combine selectively with certain solvents capable of tuning GO's amphiphilicity and regulating $\mathrm{rGO}$ formation. Zhang et al. used multiple detergents to explore surfactant-stabilized graphene-based products, such as tetra-butylammonium hydroxide (TBAOH), bromide of cetyltrimethylammonium, and sulfonate of sodium dodecyl benzene [162, 163]. They discovered that surfactants might intercalate the rGO sheets. The experimented specific capacity from stabilized TBAOH graphene was $194 \mathrm{Fg}^{-1}$. For example, at the current density of $1 \mathrm{Ag}^{-1}$ of super-capacitor electrode, which result to a reduced degree of $\mathrm{rGO}$ re-stacking and enhanced wettability in the manner of the preservative intercalation? Super-capacitor electrodes produced from graphene powders usually display elevated power density, superb electrical conductivity owing to high surface area and rapidly charging [164]. In terms of the small capacity value $\left(\sim 200 \mathrm{Fg}^{-1}\right)$, they are limited. Consequently, the device's energy density and general effectiveness are generally dissatisfied. Furthermore, the quasi-capacity acquired from other transition metal oxides (i.e. Ruthenium oxide $\left(\mathrm{RuO}_{2}\right)$, manganese dioxide $\left(\mathrm{MnO}_{2}\right), \mathrm{NiO}, \mathrm{CO}_{3} \mathrm{O}_{4}$ and $\mathrm{Fe}_{3} \mathrm{O}_{4}$ ) or hydroxides $\left(\mathrm{Ni}(\mathrm{OH})_{2}\right.$ and Cobalt(II) hydroxide $\left.\left\{\mathrm{Co}(\mathrm{OH})_{2}\right)\right\}$ as well as highly conductive polymers (i.e., PANI, poly-pyrrole and poly-thiophenes) as a byproduct of diagnosable faradaic redox reactions on the electrode coating, important accurate capabilities are demonstrated. The main electrolytic ingredients in EDLCs are carbon-based materials, i.e. graphene [165-169]. By using metal oxides/ hydro-oxides or some conductive polymer is also best way is to fabricate hybrid electrodes with the graphene wires to scale the EDLC and pseudo-capacity effectively sequentially. Graphene will work as a conductive charge transfer membrane in the hybrid electrodes and thus enhanced overall conductivity, while metal oxides/hydroxides or conductive polymers produce pseudo-capacity. Graphene- $\mathrm{MnO}_{2}$ composites were extensively researched among the metal oxide composites $[159,170]$. Yang et al. created a clear strategy to the preparing of hydrothermal reduction graphene- $\mathrm{MnO}_{2}$ Nano-composites. Graphene$\mathrm{MnO}_{2}$ Nano-composite powders demonstrate un-usual capacitance value of $211.5 \mathrm{Fg}^{-1}$. The charge discharge rate is $1000 \mathrm{load} /$ discharge cycle in $\mathrm{Na}_{2} \mathrm{SO}_{4}$ electrolyte with uniformity in capacitance is $75 \%$ at a prospective scanning rate of $2 \mathrm{mVs}^{-1}$ [171]. $\mathrm{Ni}-(\mathrm{OH})_{2}$ Nano-sheets on graphene layers were synthesized by Dai et al. High specific capacity of $1335 \mathrm{Fg}^{-1}$ at current density of $2.8 \mathrm{Ag}^{-1}$ and $~ 953 \mathrm{Fg}^{-1}$ at $45.7 \mathrm{Ag}^{-1}$ was achieved from modified electrode material [172]. To maximize the graphene sheet potential, an approach is to effectively load some of the Nano-crystal graphene skin oxide/hydroxide, which will have the dual procedure of pseudo-capacity and spacers between the graphene shades.

Novel manufacturing techniques, including spin-coating, for graphene-based sheets and papers, Langmuire Blodgett, sheet-by-layer placement, auto-assembly design and vacuum ventilation $[173,174]$, have been researched. In a comparable scenario as with the manufacturing of graphene less size films and papers is prevented by other graphene-based products by aggregation and repacking of graphene sheets. The reduction in surface area and spreading of electrolyte among graphene walls arising from inter-planar contact and van der Waals force. Appropriate spacer isolation is an efficient strategy to improving graphene sheet stacking. Pseudo-capacitive materials (e.g. transitional metal oxides, hydroxides and conductive polymers), carbon particles, CNT), metals (e.g., Pt, $\mathrm{Au}$ ) or metal oxides (e.g., $\mathrm{SnO}_{2}$ ) have been widely used as a spacer between layers [175-177]. Furthermore carbon black nanoparticles were injected to graphene layers as a spacer by wang et al. A qualified consequences were obtain ( $i, e)$. enhancement in electrochemical efficiency (i.e. a specific capacitance of $138 \mathrm{Fg}^{-1}$ in liquid electrolyte with a scanning rate of $10 \mathrm{mVs}^{-1}$ and a loss of capacitance of only $3.85 \%$ after 2000 cycles with a current density of $10 \mathrm{Ag}^{-1}$ ). To stop restoring the inner sheet $\mathrm{Li}$ et al. introduced a versatile graphene film paper that utilizes CNTs as a stabilizer. Which result high specific capacitance $140 \mathrm{Fg}^{-1}$ at current density of $0.1 \mathrm{Ag}^{-1}$. Many researchers have reported different types of separator between graphene sheets to improve the capacitance and energy density. Like Pt, $\mathrm{SnO}_{2}, \mathrm{Ni}(\mathrm{OH}), \mathrm{Ni}(\mathrm{OH})_{2}, \mathrm{Co}(\mathrm{OH})_{2}, \mathrm{MnO}_{2}[172,175,176,178]$ 

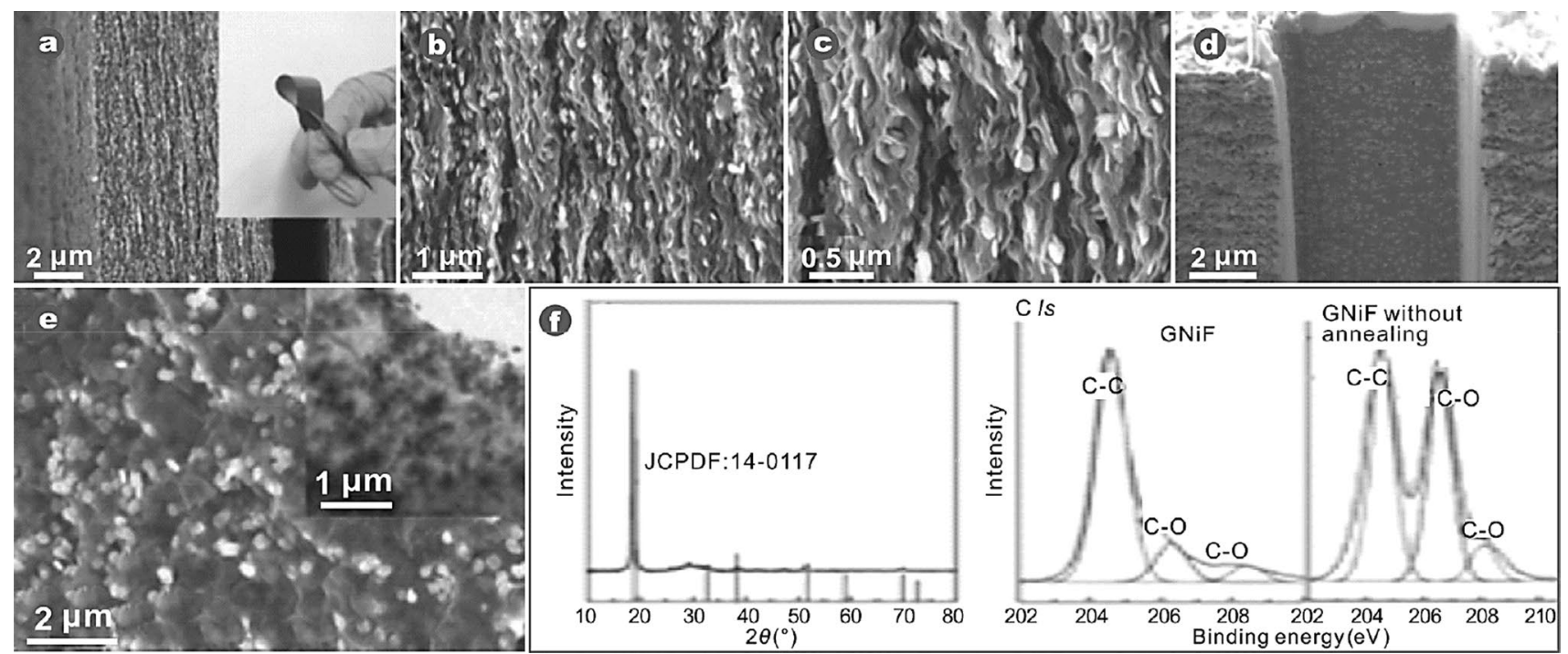

Fig. 16 "Graphene sheets intercalated with $\mathrm{Ni}(\mathrm{OH})_{2}$ Nano-plates is characterized by anatomical features and composition a-c Boundary-sectional GNiF SEM pictures with distinct magnifications, inset GNiF optical pictures displaying their flexibility, $\mathbf{d}$ Side profile of the
GNiF focused-ion beam in equal orientation to the layers of graphene e In-plane regarded GNiF's SEM and TEM (inset) diagonal to graphene sheets, $\mathbf{f}$ GNiF's XRD structure and XPS spectra" [182] and also transition metals are used as spacers in graphene sheets such as $\mathrm{CO}_{3} \mathrm{O}_{4}, \mathrm{Fe}_{3} \mathrm{O}_{4}, \mathrm{Cu}-\mathrm{O}, \mathrm{Ni}(\mathrm{OH})_{2}, \mathrm{MnO}_{2}, \mathrm{RuO}_{2}$ and conductive polymers such as polyanilines (PANI), polypyrrole (PPy) and polythiophene (PT) [179-181]. The structural morphologies of intercalated graphene with $\mathrm{Ni}$ $(\mathrm{OH})_{2}$ are shown in Fig. 16.

Nano-composite graphene thin-films involving visiting nanoparticles in 2D graphene sheets can help to reduce graphene expenditure. To address this further, many attempts have been made to create Nano-structures based on graphene with 3D narrow materials like, porous ultra-light material, graphene spume and surf [183-185]. All such 3D graphene-based substances are made of micro-meso and macro-connected pores, huge surface regions and high rate of ion/electron transport channel. To improve efficiency these factors are essential for research into high power and energy as well as overall super-capacity improvements $[186,187]$. Around most of these 3D graphene buildings showed outstanding electrochemical behavior for energy storage and other functional properties such as physical and catalytic [188]. Innumerable production techniques for preparing supercapacitor electrodes based on 3D graphene have been verified. For instance, to synthesize 3-dimensional macroporous bubble graphene soap a template-driven insertion technique was deployed. The as produced 3D bubble graphene materials show controllable and relatively constant macro-pores outstanding microstructure, which leads to high capacity rate of $67.9 \%$ with a scrutinize speed of up to $1000 \mathrm{mVs}^{-1}$. Graphene aerogels (GAs) and hydro-gels are a distinctive group of super-light, permeable carbon-based goods with higher strength-to-weight and large volume proportions [189, 190]. Mullen et al. exhibited a sophisticated model machine of elevated-performance electrode parts co-doped with boron and nitrogen relying on $3 \mathrm{D}$ mono-lithic graphene aerogels (BN-GAs) (see Fig. 17). An improved density of $\sim 8.65 \mathrm{Whkg}^{-1}$ to $\sim 1600 \mathrm{Wkg}^{-1}$ are consequences of $\mathrm{BN}-\mathrm{GAs}$ derived electrodes having a uniform mechanical strength of $\sim 62 \mathrm{Fg}^{-1}$ and outstanding ability [183].

Among super-capacitor electrode materials, $\mathrm{MnO}_{2}$ has been widely researched owing to its low price, natural availability, high theoretical capability (almost $1370 \mathrm{Fg}^{-1}$ ) and low toxicity [191]. In 1999, Lee and Goodenough first used amorphous $\mathrm{MnO}_{2}$ and $\mathrm{H}_{2} \mathrm{O}$ as possible electrode for super-capacitors in a light $\mathrm{KCl}$ liquid solution, with a capacity of about $200 \mathrm{Fg}^{-1}$ was achieved [192]. $\mathrm{MnO}_{2}$-based electrodes capacity can be enhanced by various techniques have been used to explore the synthesis of nanostructured $\mathrm{MnO}_{2}$-based electrodes, with revolutionary morphologies, permeable monolithic structures, large quantities of pores and high particular thickness. Until now, manganese oxides have been manufactured with different structures and morphologies such as Nano-sheets, [193] Nano-spheres, [194] Nano-flowers [195] nanowires/ Nano-rods, [196] thin films, [197] and Nano-tubes [198], and their electrochemical features have been explored. Studies have shown that $\mathrm{MnO}_{2}$-based Nano-materials with manageable particle size, morphology, crystallinity, highspecific thickness, and excellent electrical conductivity are 

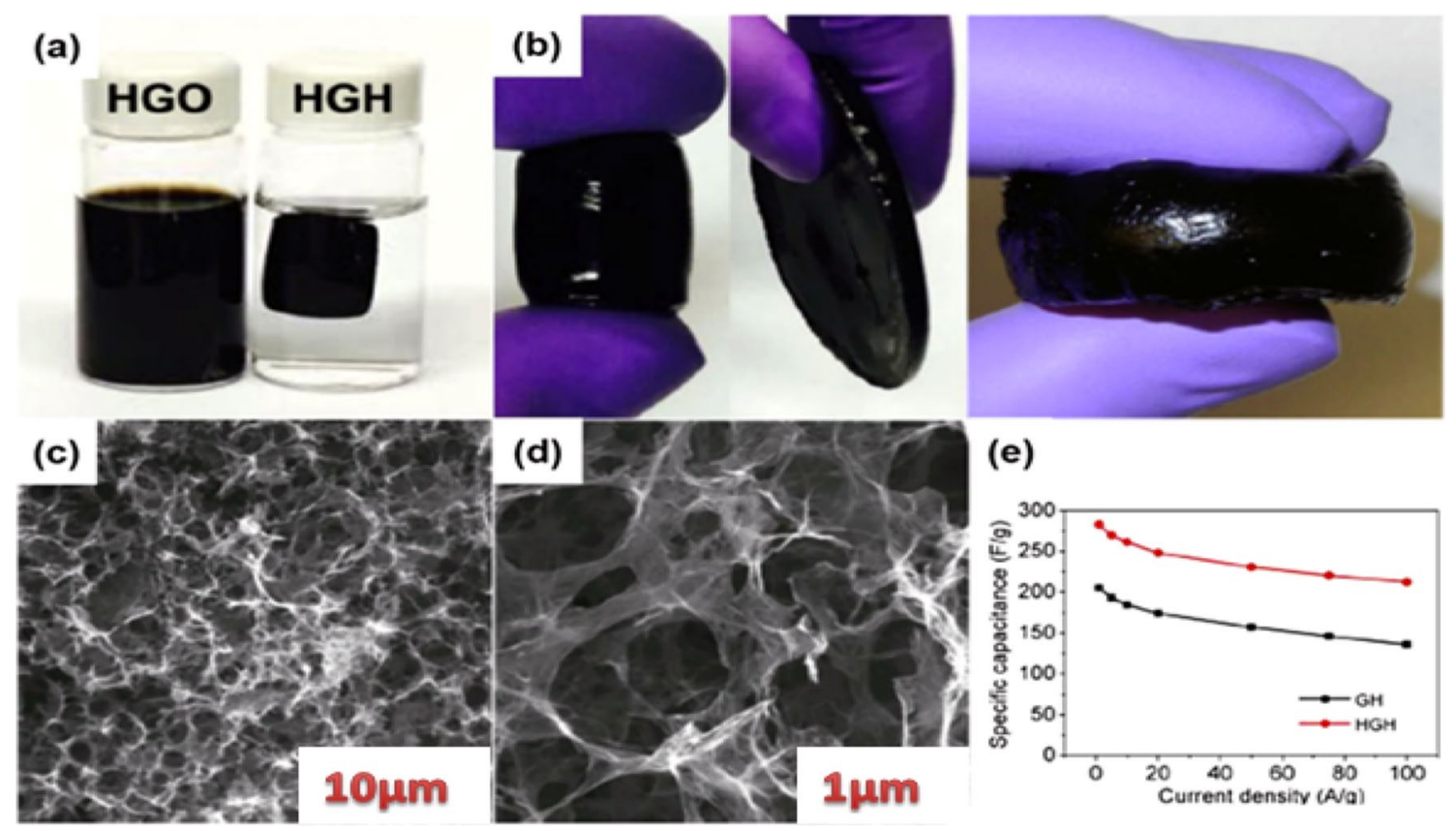

Fig. $17 \mathrm{HGH}$ preparedness and description. a Aqueous distribution photographs $(2 \mathrm{mg} / \mathrm{mL})$ of $\mathrm{HGO}$ and synthesized image of HGO. b Design of various sizes of a series of HGHs. c Large- and d less-mag- nification scanning electron microscopic images of freeze-dried $\mathrm{HGH}$ inside microstructures. e Specific capacity compare to present density [183]

prepared by top down techniques that's mechanical exfoliation, micromechanical cleavage, electrochemical reduction etc. have the following advantages, large size and unmodified graphene sheets, inexpensive, single step functionalization and exfoliation, high electrical conductivity of functionalized graphene respectively.

The effective implementation of graphene and/or other 2D materials in products depends not only on identifying the right products for new and existing applications, but also on making one of the materials at a lower cost in huge quantities. The progress made over the previous few years in creating new material procedures has been remarkable, particularly considering the wide demands of materials, from single crystal graphene to graphene clumps. It is possible to remove the cultivated graphene from the ground using an electrochemical tread separation from the copper substructure. As result, substrate of copper can be used constantly. Arrays of single-crystal graphene islands over $10 \mathrm{~mm}$ in size were achieved $[203,204]$. Graphene wet-transferred room temperature Raman spectra on three separate substrates $\left(\mathrm{Cu}, \mathrm{SiO}_{2} /\right.$ $\mathrm{Si})$ shows the basic Raman modes of graphene at about $1580 \mathrm{~cm}^{-1}$ due to the inner vibration of C-C bond. Small differences can be ascribed to substrate doping impacts in the room temperature peak locations and full-widthto-half maxima in the $G$ and 2D peaks [205]. Researchers used the graphene TEC (thermal expansion coefficient) from Mounet et al. theoretical work to get the theoretical

\section{SN Applied Sciences


frequency change due to strain, while the $\mathrm{SiO}_{2}$ and $\mathrm{Cu}$ TEC values are extracted from the literature $[206,207]$. The CVD process that scientists use for the production of graphene only takes 66 min without making use of vacuum pumps. The process is completed in four stages (cleaning, precursor injection, reaction time, and cooling). The use of saturated and unsaturated hydrocarbons is crucial for CVD graphene synthesis [208, 209]. $\mathrm{C}_{2} \mathrm{H}_{2}$ has a favorable free energy development of Gibbs with a value of approximately $=209 \mathrm{~kJ} / \mathrm{mol}$, suggesting that reactants are favored in the following reaction: $2 \mathrm{C}+\mathrm{H}_{2}=\mathrm{C}_{2} \mathrm{H}_{2}$ [209]. Using dark and light field illumination mode, typical micrographs can be achieved by electron beam microscopy. The findings indicate sheets pulled up during sonication from $\mathrm{Cu}$ substrates. This impact can be ascribed to the balancing of carbon particles in nucleation centers that prevent graphene sheet epitaxial development. Likewise, carbonaceous agglomerates are observed in process at $800^{\circ} \mathrm{C}$ on a graphene sheet indicating the low-temperature accumulation hypothesis. Raman spectroscopy was performed to assess the graphene film growth structure under distinct circumstances. This spectroscopy method was used to test the structural and physical characteristics of graphic products, giving useful data on the atomic edge structure, disorder presence, faults, loads and strain [210]. In the applications of graphene, we discuss Super-capacitor. Stimulated microwave expanded graphite oxide have a big portion of micro and meso-porous so when this graphene use in super-capacitor, it provides big and available region to accommodate charges, which in turn increase the specific capacity of super capacitor. There is a greater influence of graphene and graphene-based materials on the energy density of super-capacitors. Every material has different values of energy capacity. By using graphene, the specific capacity obtained is $117 \mathrm{Fg}^{-1}$. The specific capacity property can be enhanced by doping different materials in graphene. Composite materials can be used to improve the energy density like, $\mathrm{Mg}-\mathrm{O}, \mathrm{Fe}_{3} \mathrm{O}_{4}, \mathrm{MnO}_{2}$ and cobalt oxides. Graphene can be folded into many shapes for example quantum dots, 1D, 2D or 3D which shows different values of energy density. Zhang et al. used graphene dots with various detergents and obtained a specific capacity of $194 \mathrm{~F} \mathrm{~g}^{-1}$. Some transition metals oxides have also shown dramatic capacity i.e. $\mathrm{MnO}_{2}, \mathrm{RuO}_{2}, \mathrm{NiO}, \mathrm{CO}_{3} \mathrm{O}_{4}$ and $\mathrm{Fe}_{3} \mathrm{O}_{4}$. Yang et al. developed an obvious way for the production of $\mathrm{MnO}_{2}$, which display a specific capacity of $211.5 \mathrm{Fg}^{-1}$. Similarly, Dai et al. use nickel hydro-oxide $\left(\mathrm{Ni}(\mathrm{OH})_{2}\right)$ Nanolayer on graphene films showing a strong specific capacity of $1335 \mathrm{Fg}^{-1}$. A study group led by Tokyo University in Japan has created new materials with greater voltage and greater stability than other materials for super-capacitors. Activated carbons are used in condensers for electrodes, but they are constrained in single cells by low voltage, the building blocks that make up condensers. The new material is a layer made of a constant three-dimensional graphene meso-sponge structure, a carbon-based material that contains pores of Nano-scale. Using electron microscopy and a variety of physical exams, including $X$-ray diffraction and vibrational spectroscopy methods, the scientists explored the physical characteristics of their new material. They demonstrate that the material had outstanding flexibility in a standard organic electrolyte at elevated temperatures of $60^{\circ} \mathrm{C}$ and high voltage of $3.5 \mathrm{~V}$. It demonstrated ultra-high stability at $25^{\circ} \mathrm{C}$ and $4.4 \mathrm{~V}, 2.7$ times greater than standard activated carbons and other materials based on graphene [211].

\section{Limitations}

When graphene is used as a catalyst its susceptibility is oxidative to environment. For growth of graphene, toxic material is used at high temperature due to this it exhibits some toxic qualities. Graphene has super-sharp edges that can readily penetrate the cell membrane, enter the cell and interfere with ordinary functions, production of large graphene sheets is difficult to achieve [212].

Graphene by itself is unsuitable for interaction with polymers chain because graphene is hydrophobic [213], so there is a high probability of graphene to pile in a polymer matrix, so to remove this agglomeration of graphene in polymer matrix modification of graphene using chemical, electrochemical, pi-pi interaction [214] is usually needed. Organic molecules can be the functional groups connected to graphene or polymer chains $[214,215]$. To remove the accumulation of graphene from Al sheets, accumulative roll binding process [216]. Another set was prepared with same process in the absence of graphene coating. The main aim of these two samples is to study the effect of graphene. After that, sample was subjected to SEM, by observation it concludes that agglomeration of graphene is found less in this process. Transition metals as super-capacitor electrodes have great influence on capacitance. For example $\mathrm{RuO}_{2}$ shows elevated capacitance and reliable life range, however it is very expensive to use. Next $\mathrm{MnO}_{2}$ has super properties like low cost, elevated specific capacity, long life cycle, but its low electrical conductivity and unstable mechanical structure make its use limited. Furthermore $\mathrm{Mn}_{3} \mathrm{O}_{4}$ as super-capacitor electrode material has limitation because of less conduction. There are certain kinds of limitations in graphene based Nanocomposites that can be great challenge to overcome like stability of structure, low conductivity, corrosion, transition in phase. Complication process was used to fabricate $\mathrm{Cu}_{2} \mathrm{O}$ on graphene oxide sheet. The as- produced product have showed initial capacity of $1100 \mathrm{mAhg}^{-1}$. While 
bad cycling makes this material unreliable in its present shape. Copper mixtures will be complicated because the $\mathrm{Cu}^{+2}$ oxidation state in several organic solvents is quickly disproportionate. Graphene based metallic materials were found agglomerated on graphene surfaces. To overcome these issues graphene based metal matrices composites prepared via by ball milling and hot-press sintering can produced homogenous mixture [217]. In these composites main problem is very low bonding between graphene and metallic matrices and limitation of full densification for bulk matrix composites, this hardship is depend on its preparation method, most useful method is powder metallurgy [218].

\section{Conclusion}

Regarding the outstanding and unusual characteristics of graphene, it is one of the best materials known which can be used for different purposes. Many areas are inspired by graphene like industrial areas, electronics, optoelectronics, flexible electronics and wearable electronics. Particularly for energy storage devices like batteries and super-capacitors, where graphene can be deployed as electrode material to absorb, store and release huge amount of energy for uses. Furthermore, graphene-based metal composites also have the property to enhance the capacity and energy density of super-capacitor. Various techniques has been used to fabricate scalable and best product like, chemical vapor deposition (CVD) chemical exfoliation, mechanical exfoliation and growth on different substrate materials like copper (Cu), nickel (Ni) graphene composites fabricated through plasma enhanced chemical vapor deposition are very expensive and need high temperature. Also roll to roll method with microwave assisted CVD technique is used to produce large scale composites, but due to its less efficiency it is not that much reliable. Graphene composites prepared through micromechanical cleavage cannot be used industrially because this process is time consuming. The best quality graphene can be obtained through CVD process having feature of manageable layers and CVD has also the ability to fabricate huge amount of graphene. Graphene shows capacitance of $135 \mathrm{Fg}^{-1}$ and $117 \mathrm{Fg}^{-1}$ when used in aqueous electrolyte and aqueous $\mathrm{H}_{2} \mathrm{SO}_{4}$ respectively. $\mathrm{MgO}_{2}, \mathrm{Mg}-\mathrm{O}, \mathrm{FeSO}_{4}, \mathrm{MnO}_{2}$ cobalt oxide was studied and capacitance of $76.3 \mathrm{whkg}^{-1}$. TBAOH based graphene was examined which shows $194 \mathrm{Fg}^{-1}$ of capacitance by intercalation of more graphene the capacity was increased to $200 \mathrm{Fg}^{-1}$. At a current density of $2.8 \mathrm{Ag}^{-1}$, $\mathrm{Ni}(\mathrm{OH})_{2}$ Nano-sheets on graphene layer shows high capacity of $1335 \mathrm{Fg}^{-1}$. Also different dimension of graphene based materials can be used for the electrodes of super-capacitors like zero dimensional dots, 1D yarn, 2D and $3 \mathrm{D}$ respectively.

\section{Compliance with ethical standards}

Conflict of interest The authors declare that they have no competing interests

\section{References}

1. Wang W et al (2019) T4, 4, 4-graphyne: a 2D carbon allotrope with an intrinsic direct bandgap. Solid State Commun 293:23-27

2. Rojas WY et al (2018) Strain and bond length dynamics upon growth and transfer of graphene by NEXAFS spectroscopy from first-principles and experiment. Langmuir 34(4):1783-1794

3. Azari M, Kirczenow G (2018) Valley filters, accumulators, and switches induced in graphene quantum dots by lines of adsorbed hydrogen atoms. Phys Rev B 97(24):245404

4. González Z et al (2018) Influence of the electrophoretic deposition parameters on the formation of suspended graphenebased films. Mater Des 160:58-64

5. Salifairus M et al. (2018) The synthesis of graphene at different deposition time from palm oil via thermal chemical vapor deposition. In: AIP conference proceedings. AIP Publishing

6. Kashani $\mathrm{H}$ et al (2019) Extraordinary tensile strength and ductility of scalable nanoporous graphene. Sci Adv 5(2):eaat6951

7. Sehrawat P, Islam S, Mishra P (2018) Reduced graphene oxide based temperature sensor: extraordinary performance governed by lattice dynamics assisted carrier transport. Sens Actuators B Chem 258:424-435

8. Hamam AM et al (2018) Sub-10 nm graphene nano-ribbon tunnel field-effect transistor. Carbon 126:588-593

9. Fan Y et al (2019) Graphene plasmonics: a platform for 2D optics. Adv Opt Mater 7(3):1800537

10. Hemanth $S$ et al (2018) 3D Carbon microelectrodes with biofunctionalized graphene for electrochemical biosensing. Biosensors $8(3): 70$

11. Feng $C$ et al (2018) Tuning micro-wrinkled graphene films for stretchable conductors of controllable electrical conductivity. Carbon 139:672-679

12. Sangwan VK, Hersam MC (2018) Electronic transport in twodimensional materials. Ann Rev Phys Chem 69:299-325

13. Navarro J et al (2018) Graphene catalyzes the reversible formation of a C-C bond between two molecules. Sci Adv 4(12):eaau9366

14. Zhong T, Li J, Zhang K (2019) A molecular dynamics study of Young's modulus of multilayer graphene. J Appl Phys 125(17): 175110

15. Li XL, Guo JG (2019) Theoretical investigation on failure strength and fracture toughness of precracked single-layer graphene sheets. J Nanomater. https://doi.org/10.1155/2019/9734807

16. Ahmad M, Naz S (2019) Graphene-based composite nanostructures: synthesis, properties, and applications. Handbook of graphene composites. https://doi.org/10.1002/9781119468455

17. Lu Y, Liu X, Kuzum D (2018) Graphene-based neurotechnologies for advanced neural interfaces. Curr Opin Biomed Eng 6:138-147

18. Shunin Y et al. (2018) Graphene, fullerenes, carbon nanotubes: electronic subsystem. In: Nonregular nanosystems. Springer, $\mathrm{p}$ 253-286 
19. Kakaei K, Esrafili MD, Ehsani A (2019) Atomic properties and electronic structure, in interface science and technology. Elsevier, p 23-66

20. Matochova D et al (2018) 2D chemistry: chemical control of graphene derivatization. J Phys Chem Lett 9(13):3580-3585

21. Chang J-H (2018) Polyimide nanocomposites with functionalized graphene sheets: thermal property, morphology, gas permeation, and electroconductivity. J Thermoplast Compos Mater 31(6):837-861

22. Vlassiouk IV, Ivanov IN, Datskos PG (2018) Graphene reinforced materials and related methods of manufacture. Google Patents

23. Santhosha AL et al (2019) Exfoliated MoS2 as electrode for all solid state rechargeable lithium-ion batteries. J Phys Chem C 123:12126

24. Yankowitz M et al (2019) van der Waals heterostructures combining graphene and hexagonal boron nitride. Nat Rev Phys 1(2):112-125

25. Ji Y, Wei Q, Sun $Y$ (2018) Superior capacitive performance enabled by edge-oriented and interlayer-expanded MOS2 nanosheets anchored on reduced graphene oxide sheets. Ind Eng Chem Res 57(13):4571-4576

26. Omambac KM et al (2019) Temperature-controlled rotational epitaxy of graphene. Nano Lett 19:4594

27. Zhang $\mathrm{N}$ et al (2019) Bifacial Raman enhancement on monolayer two-dimensional materials. Nano Lett 19(2):1124-1130

28. El Sachat A et al (2019) Crossover from ballistic to diffusive thermal transport in suspended graphene membranes. 2D Materials 6(2):025034

29. Anzi $L$ et al (2018) Ultra-low contact resistance in graphene devices at the Dirac point. 2D Materials 5(2):025014

30. Baudisch $\mathrm{M}$ et al (2018) Ultrafast nonlinear optical response of Dirac fermions in graphene. Nat Commun 9(1):1018

31. Zhu M et al (2018) Supercurrent and multiple Andreev reflections in micrometer-long ballistic graphene Josephson junctions. Nanoscale 10(6):3020-3025

32. Sezer N, Khan SA, Koç M (2019) Amelioration of the pool boiling heat transfer performance via self-assembling of 3D porous graphene/carbon nanotube hybrid film over the heating surface. Int J Heat Mass Transf 145:118732

33. Bhattacharya $S$ et al (2018) A comprehensive dual beam approach for broadband control of ultrafast optical nonlinearity in reduced graphene oxide. Carbon 134:80-91

34. Savazzi F et al (2018) Unravelling some of the structure-property relationships in graphene oxide at low degree of oxidation. J Phys Chem Lett 9(7):1746-1749

35. Wang $X$ et al (2017) MoS2/polymer nanocomposites: preparation, properties, and applications. Polym Rev 57(3):440-466

36. Rathod UP et al (2019) Growth of pulsed laser deposited few-layer WS2 films. J Vacuum Sci Technol A Vac Surf Films 37(5):051505

37. Liu G et al (2019) Preparation and comparison of nonlinear optical properties of MoSe2 with different types of structures. Opt Mater 95:109240

38. Pathak $\mathrm{M}$ et al (2020) A comparative experimental and theoretical investigation on energy storage performance of $\mathrm{CoSe} 2$, $\mathrm{NiSe} 2$ and $\mathrm{MnSe} 2$ nanostructures. Appl Mater Today 19:100568

39. Liu C et al (2019) Enhanced mechanical and tribological properties of graphene/bismaleimide composites by using reduced graphene oxide with non-covalent functionalization. Compos B Eng 165:491-499

40. Navasingh RJH et al. (2019) Graphene-based nano metal matrix composites: a review. In: Nanocarbon and its composites. Elsevier. p 153-170

41. Xiang $S$ et al (2017) Enhanced overall strength and ductility of magnesium matrix composites by low content of graphene nanoplatelets. Compos A Appl Sci Manuf 100:183-193
42. Yuan Q-H et al (2018) Interfacial structure in AZ91 alloy composites reinforced by graphene nanosheets. Carbon 127:177-186

43. Yuan Q-H et al (2018) Interfacial design and strengthening mechanisms of AZ91 alloy reinforced with in situ reduced graphene oxide. Mater Charact 138:215-228

44. Zhang $\mathrm{H}$ et al (2016) Enhanced mechanical properties of Al5083 alloy with graphene nanoplates prepared by ball milling and hot extrusion. Mater Sci Eng, A 658:8-15

45. Clyne T, Hull D (2019) An introduction to composite materials. Cambridge University Press, Cambridge

46. Yu Q et al (2016) Bending deformation of laser peened aluminium alloy with uniform rectangular spots. Mater Sci Technol 32(1):9-14

47. Şenel MC, Gürbüz M, Koç E (2018) Effect of graphene content on tensile strength and microstructure of aluminum matrix composites. Univ J Mater Sci 6:79

48. Rashad M, Pan F, Asif M (2015) Magnesium matrix composites reinforced with graphene nanoplatelets. Graphene materials: fundamentals and emerging applications. John Wiley \& Sons, New Jersey, pp 151-189

49. Rashad M et al (2015) Improved strength and ductility of magnesium with addition of aluminum and graphene nanoplatelets $(\mathrm{Al}+\mathrm{GNPs}$ ) using semi powder metallurgy method. J Ind Eng Chem 23:243-250

50. Rashad M et al (2015) Development of magnesium-graphene nanoplatelets composite. J Compos Mater 49(3):285-293

51. Hu Z et al (2018) 3D printing graphene-aluminum nanocomposites. J Alloy Compd 746:269-276

52. Guan R et al (2019) Fabrication of aluminum matrix composites reinforced with $\mathrm{Ni}$-coated graphene nanosheets. Mater Sci Eng, A 754:437-446

53. Mohan VB et al (2018) Graphene-based materials and their composites: a review on production, applications and product limitations. Compos B Eng 142:200-220

54. Byun $\mathrm{M}$ et al (2019) Characterization of copper-graphite composites fabricated via electrochemical deposition and spark plasma sintering. Appl Sci 9(14):2853

55. Behera AK, Mallik A (2018) Ultrasound assisted electroplating of nano-composite thin film of Cu matrix with electrochemically in-house synthesized few layer graphene nano-sheets as reinforcement. J Alloy Compd 750:587-598

56. Singh $S$ et al. (2019) Hybrid carbon nanostructures for chemical and biological sensors. In: Advanced biosensors for health care applications. Elsevier, p 357-374

57. Yoo SC, Lee J, Hong SH (2019) Synergistic outstanding strengthening behavior of graphene/copper nanocomposites. Compos B Eng 176:107235

58. Wang $X$ et al. (2018) Characterization of graphene/Cu composites prepared by CVD and SPS. In: Chinese materials conference. Springer

59. Kumari S et al (2019) Electrochemical behavior of nanostructured graphene nickel phosphorus composite coating on copper. J Appl Electrochem 49:1157-1166

60. Yasin G et al (2018) Synthesis of spheres-like Ni/graphene nanocomposite as an efficient anti-corrosive coating; effect of graphene content on its morphology and mechanical properties. J Alloy Compd 755:79-88

61. Jiang J et al (2018) In-situ fabrication of graphene-nickel matrix composites. Mater Lett 220:178-181

62. Maddi $C$ et al (2018) Nano-architecture of nitrogen-doped graphene films synthesized from a solid CN source. Sci Rep $8(1): 3247$

63. Xue $Y$ et al (2018) Formation mechanism and cohesive energy analysis of metal-coated graphene nanocomposites using in situ co-reduction method. Materials 11(11):2071 
64. Hu Z et al (2018) Fabricating graphene-titanium composites by laser sintering PVA bonding graphene titanium coating: microstructure and mechanical properties. Compos B Eng 134:133-140

65. Zhang Q et al (2019) Synthesis of $\mathrm{Fe}-\mathrm{Ni} /$ graphene oxide composite and its highly efficient removal of uranium ( $\mathrm{VI}$ ) from aqueous solution. J Clean Prod 230:1305-1315

66. Alemour B et al (2018) Review of electrical properties of graphene conductive composites. Int J Nanoelectron Mater 11(4):371

67. Darabdhara G et al (2019) Ag and Au nanoparticles/reduced graphene oxide composite materials: synthesis and application in diagnostics and therapeutics. Adv Coll Interface Sci 271:101991

68. Nancy P et al (2019) In situ decoration of gold nanoparticles on graphene oxide via nanosecond laser ablation for remarkable chemical sensing and catalysis. Nanomaterials 9(9):1201

69. Yang $C$ et al (2019) One-step synthesis of size-tunable gold nanoparticles/reduced graphene oxide nanocomposites using argon plasma and their applications in sensing and catalysis. Appl Surf Sci 473:83-90

70. Fu Y et al (2018) Graphene blended with $\mathrm{SnO}_{2}$ and Pd-Pt nanocages for sensitive non-enzymatic electrochemical detection of $\mathrm{H}_{2} \mathrm{O}_{2}$ released from living cells. Anal Chim Acta 1014:10-18

71. Liu T et al (2019) Few-layered boron nitride nanosheets as superior adsorbents for the rapid removal of lead ions from water. J Mater Sci 54(7):5366-5380

72. Sadhukhan S et al (2019) Green synthesis of cadmium oxide decorated reduced graphene oxide nanocomposites and its electrical and antibacterial properties. Mater Sci Eng, C 99:696-709

73. Wang $Z$ et al (2019) Lithium photo-intercalation of CdS-sensitized WO3 anode for energy storage and photoelectrochromic applications. Chem Sus Chem 12:2220

74. Zhang Z et al (2018) Ultrasensitive ppb-level $\mathrm{NO}_{2}$ gas sensor based on WO3 hollow nanosphers doped with Fe. Appl Surf Sci 434:891-897

75. Ferrari VC et al (2018) Photoactive multilayer WO3 electrode synthesized via dip-coating. Ceram Int 44(18):22983-22990

76. He X et al (2019) Synthesis of three-dimensional hierarchical urchinlike tungsten trioxide microspheres for high-performance supercapacitor electrode. Crystals 9(9):485

77. Yang Z et al (2019) Facile synthesis of reduced graphene oxide/tungsten disulfide/tungsten oxide nanohybrids for high performance supercapacitor with excellent rate capability. Appl Surf Sci 463:150-158

78. Wong CPP, Lai CW, Juan JC (2018) Hydrothermal synthesis of supercapacitors electrode materials. Electrochem Capacit Theory Mater Appl 26:209

79. Hadjittoouli N. et al. (2018) Solution processed WO3 for electrochromic applications. Structure and properties. In: 7th International symposium on transparent conductive materials

80. Zhao T et al (2019) Facile synthesis of mesoporousWO3@ graphene aerogel nanocomposites for low-temperature acetone sensing. Chin Chem Lett 30:2032

81. Liang YC, Chang C-W (2019) Preparation of orthorhombic WO3 thin films and their crystal quality-dependent dye photodegradation ability. Coatings $9(2): 90$

82. Xu W (2018) Nanoscale design and engineering of electrocatalysts in fuel cell and water electrolyzer energy conversion. New Mexico State University, Las Cruses

83. Wong CPP et al (2016) Synthesis of reduced graphene oxide/ tungsten trioxide nanocomposite electrode for high electrochemical performance. Ceram Int 42(11):13128-13135
84. Shinde PA et al (2019) Facile synthesis of self-assembled WO3 nanorods for high-performance electrochemical capacitor. J Alloy Compd 770:1130-1137

85. Huang $Y$ et al (2019) Simple synthesis of 1D, 2D and 3D WO3 nanostructures on stainless steel substrate for high-performance supercapacitors. J Alloy Compd 778:603-611

86. Zhang J, Cui Y, Shan G (2019) Metal oxide nanomaterials for pseudocapacitors. arXiv preprint arXiv:1905.01766

87. Periasamy P et al (2018) Investigation of electrochemical properties of microwave irradiated tungsten oxide (WO3) nanorod structures for supercapacitor electrode in $\mathrm{KOH}$ electrolyte. Mater Res Express 5(8):085007

88. Wu C-M et al (2019) Recent advances in tungsten-oxide-based materials and their applications. Front Mater 6:49

89. Yang $\mathrm{F}$ et al (2018) Fabrication of WO3.2H2O/BC hybrids by radiation method for enhanced performance supercapacitors. Front Chem 6:290

90. Zheng $\mathrm{F}$ et al (2019) Facile preparation of WO3 nano-fibers with super large aspect ratio for high performance supercapacitor. J Alloy Compd 772:933-942

91. Plata JJ et al (2019) Understanding the photocatalytic properties of $\mathrm{Pt} / \mathrm{CeO} / \mathrm{TiO} 2$ : structural effects on electronic and optical properties. ChemPhysChem 20(12):1624-1629

92. Li S et al (2018) Three-dimensional hierarchical graphene/ $/ \mathrm{TiO}_{2}$ composite as high-performance electrode for supercapacitor. J Alloy Compd 746:670-676

93. Wei $Z$ et al (2019) Porous nanorods of nickel-cobalt double hydroxide prepared by electrochemical co-deposition for highperformance supercapacitors. J Colloid Interface Sci 542:15-22

94. Meng X, Lu L, Sun C (2018) Green synthesis of three-dimensional $\mathrm{MnO}_{2}$ /graphene hydrogel composites as a high-performance electrode material for supercapacitors. ACS Appl Mater Interfaces 10(19):16474-16481

95. Abbas WA et al (2019) Recent advances in the use of $\mathrm{TiO}_{2}$ nanotube powder in biological, environmental, and energy applications. Nanoscale Adv 1(8):2801-2816

96. Li W et al (2019) An important factor affecting the supercapacitive properties of hydrogenated $\mathrm{TiO}_{2}$ nanotube arrays: crystal structure. Nanoscale Res Lett 14(1):229

97. Pal B et al (2018) Hydrothermal syntheses of tungsten doped $\mathrm{TiO}_{2}$ and $\mathrm{TiO}_{2} / \mathrm{WO} 3$ composite using metal oxide precursors for charge storage applications. J Alloy Compd 740:703-710

98. Gawri l et al. 2019 Dielectric and conductivity studies of in situ oxidative polymerized PANI@ TiO2 nanocomposite. In: AIP conference proceedings. AIP Publishing

99. Li J et al (2019) N-doped TiO2/rGO hybrids as superior Li-ion battery anodes with enhanced Li-ions storage capacity. J Alloy Compd 784:165-172

100. Salari M et al (2018) Tubular $\mathrm{TiO}_{2}$ nanostructures: toward safer microsupercapacitors. Adv Mater Technol 3(2):1700194

101. Naeem $\mathrm{F}$ et al (2019) $\mathrm{TiO}_{2}$ nanomembranes fabricated by atomic layer deposition for supercapacitor electrode with enhanced capacitance. Nanoscale Res Lett 14(1):92

102. Police AKR et al (2018) Single-step hydrothermal synthesis of wrinkled graphene wrapped $\mathrm{TiO}_{2}$ nanotubes for photocatalytic hydrogen production and supercapacitor applications. Mater Res Bull 98:314-321

103. Nagaraju P et al (2018) Facile in situ microwave irradiation synthesis of $\mathrm{TiO}_{2} /$ graphene nanocomposite for high-performance supercapacitor applications. J Electroanal Chem 808:90-100

104. Grillo F et al (2018) Oriented attachment and nanorod formation in atomic layer deposition of $\mathrm{TiO}_{2}$ on graphene nanoplatelets. J Phys Chem C 122(34):19981-19991

105. Sagadevan $S$ et al (2018) A facile hydrothermal approach for catalytic and optical behavior of tin oxide-graphene $\left(\mathrm{SnO}_{2} / \mathrm{G}\right)$ nanocomposite. PLoS ONE 13(10):e0202694 
106. Song B et al (2018) Quantitative in situ fracture testing of tin oxide nanowires for lithium ion battery applications. Nano Energy 53:277-285

107. Leijtens $T$ et al (2018) Tin-lead halide perovskites with improved thermal and air stability for efficient all-perovskite tandem solar cells. Sustain Energy Fuels 2(11):2450-2459

108. Zhang D et al (2018) High-performance QCM humidity sensor based on graphene oxide/tin oxide/polyaniline ternary nanocomposite prepared by in situ oxidative polymerization method. Sens Actuators B Chem 262:531-541

109. Liu K-K et al (2018) Flexible solid-state supercapacitor based on tin oxide/reduced graphene oxide/bacterial nanocellulose. RSC Adv 8(55):31296-31302

110. Chen $C$ et al (2019) Solvent-assisted low-temperature crystallization of $\mathrm{SnO} 2$ electron-transfer layer for high-efficiency planar perovskite solar cells. Adv Func Mater 29:1900557

111. Salifairus M et al. (2018) The synthesis of graphene from palm oil at different annealing time of nickel substrate via thermal chemical vapor deposition. In: AIP conference proceedings. AIP Publishing

112. Berger C, Conrad E, de Heer W (2018) The electronic band structure of graphene. In: Physics of solid surfaces. Springer, pp 674-682

113. Bykkama $S$ et al (2018) A novel ultrasonic assisted synthesis of few layered graphene $/ \mathrm{SnO}_{2}$ nanocomposite and its electrochemical properties. Int J Cur Res Eng Sci Tech ISSN 2581:4311

114. Sharma V, Singh I, Chandra A (2018) Hollow nanostructures of metal oxides as next generation electrode materials for supercapacitors. Sci Rep 8(1):1307

115. Zhao T et al (2018) Facile preparation of reduced graphene oxide/copper sulfide composite as electrode materials for supercapacitors with high energy density. Compos B Eng 150:60-67

116. Song $Z$ et al (2019) One-step self-assembly fabrication of threedimensional copper oxide/graphene oxide aerogel composite material for supercapacitors. Solid State Commun 287:27-30

117. Sheikhzadeh $\mathrm{M}$ et al (2018) Nano composite foam layer of CuO/ graphene oxide (GO) for high performance supercapacitor. Synth Met 244:10-14

118. Mirzaee M, Dehghanian C, Bokati KS (2018) One-step electrodeposition of reduced graphene oxide on three-dimensional porous nano nickel-copper foam electrode and its use in supercapacitor. J Electroanal Chem 813:152-162

119. Kumar R et al (2017) Self-assembled and one-step synthesis of interconnected 3D network of Fe3O4/reduced graphene oxide nanosheets hybrid for high-performance supercapacitor electrode. ACS Appl Mater Interfaces 9(10):8880-8890

120. Lu K et al (2015) An advanced aqueous sodium-ion supercapacitor with a manganous hexacyanoferrate cathode and a $\mathrm{Fe}_{3}$ $\mathrm{O}_{4} / \mathrm{rGO}$ anode. J Mater Chem A 3(31):16013-16019

121. Li L et al (2016) Ultra small and highly dispersed $\mathrm{Fe}_{3} \mathrm{O}_{4}$ nanoparticles anchored on reduced graphene for supercapacitor application. Electrochim Acta 190:566-573

122. Yan $\mathrm{F}$ et al (2015) Fabrication of magnetic irregular hexagonal$\mathrm{Fe}_{3} \mathrm{O}_{4}$ sheets/reduced graphene oxide composite for supercapacitors. Synth Met 209:473-479

123. Du X et al (2019) Self-assembly of free-standing hybrid film based on graphene and zinc oxide nanoflakes for high-performance supercapacitors. J Solid State Chem 277:441

124. $\mathrm{Ma} \mathrm{H}$ et al (2017) Disassembly-reassembly approach to $\mathrm{RuO}_{2} /$ graphene composites for ultrahigh volumetric capacitance supercapacitor. Small 13(30):1701026

125. Huang B et al (2015) Synthesis of graphene oxide decorated with core@ double-shell nanoparticles and application for Cr(VI) removal. RSC Adv 5(129):106339-106349
126. Fang $D-L$ et al (2012) Homogeneous growth of nano-sized $\beta-\mathrm{Ni}(\mathrm{OH}) 2$ on reduced graphene oxide for high-performance supercapacitors. Electrochim Acta 81:321-329

127. Govindarajan D, Shankar VU, Gopalakrishnan R (2019) Supercapacitor behavior and characterization of RGO anchored $\mathrm{V}_{2} \mathrm{O}_{5}$ nanorods. J Mater Sci: Mater Electron 30:1-14

128. Cui Y et al (2019) Effect of the surface adsorbate of $\mathrm{SiC}$ particles on fabrication and mechanical property of aluminum matrix composite. J Mater Eng 4:21

129. Choi J-H et al (2018) High capacitance and energy density supercapacitor based on biomass-derived activated carbons with reduced graphene oxide binder. Carbon 132:16-24

130. Canal-Rodríguez M et al (2019) The role of conductive additives on the performance of hybrid carbon xerogels as electrodes in aqueous supercapacitors. Electrochim Acta 295:693-702

131. Song $Z$ et al (2018) The battery-supercapacitor hybrid energy storage system in electric vehicle applications: a case study. Energy 154:433-441

132. Martins VL, Torresi RM, Rennie AJ (2018) Design considerations for ionic liquid based electrochemical double layer capacitors. Electrochim Acta 270:453-460

133. Khan SM et al (2019) Anomalous changes of intermolecular distance in aqueous electrolytes in narrow pores of carbon nanotubes. Adsorption. https://doi.org/10.1007/s10450-01900082-w

134. Liu Y et al (2019) A template-free synthesis of porous 3D honeycomb-like carbons for supercapacitor electrodes. J Mater Sci: Mater Electron 30(6):5744-5752

135. Phan TN et al (2019) Enhanced electrochemical performance for EDLC using ordered mesoporous carbons (CMK-3 and CMK8): role of mesopores and mesopore structures. J Alloy Compd 780:90-97

136. Joseph $\mathrm{S}$ et al (2019) Highly ordered mesoporous carbons with high specific surface area from carbonated soft drink for supercapacitor application. Microporous Mesoporous Mater 280:337-346

137. Zeng F-Y et al (2018) Nitrogen-doped carbon aerogels with high surface area for supercapacitors and gas adsorption. Mater Today Commun 16:1-7

138. Wan Z et al (2018) Laser-reduced graphene: synthesis, properties, and applications. Adv Mater Technol 3(4):1700315

139. Yang $Z$ et al (2019) Carbon nanotube-and graphene-based nanomaterials and applications in high-voltage supercapacitor: a review. Carbon 141:467-480

140. Zhang J et al (2018) Microwave-assisted exfoliation strategy to boost the energy storage capability of carbon fibers for supercapacitors. J Mater Sci 53(15):11050-11061

141. Du C et al (2019) lonic liquid electrolytes for graphene-based supercapacitors with an ultrahigh energy density. Layer Mater Energy Storage Convers 34:95

142. Fan $\mathrm{S}$ et al (2018) A fast modularized multiwinding transformer balancing topology for series-connected super capacitors. IEEE Trans Power Electron 34(4):3255-3268

143. Camacho RP et al (2019) $\mathrm{Mn}_{3} \mathrm{O}_{4}$ nanoparticles encapsulated in carbon cages as the electrode of dual-mechanism supercapacitors. Mater Today Chem 12:361-372

144. Borghi F et al (2019) Quantitative characterization of the interfacial morphology and bulk porosity of nanoporous clusterassembled carbon thin films. Appl Surf Sci 479:395-402

145. Jayawickramage RAP, Balkus KJ Jr, Ferraris JP (2019) Binder free carbon nanofiber electrodes derived from polyacrylonitrilelignin blends for high performance supercapacitors. Nanotechnology 30(35):355402

146. Nonomura R et al (2018) Electrochemical capacitors using nitrogen-doped vertically aligned multi-walled carbon nanotube electrodes prepared by defluorination. Carbon 132:539-547 
147. Dupont MF et al (2018) Effect of electrolyte cation on the charge storage mechanism of manganese dioxide for electrochemical capacitors. Electrochim Acta 271:337-350

148. Xiong $P$ et al (2018) Genuine unilamellar metal oxide nanosheets confined in a superlattice-like structure for superior energy storage. ACS Nano 12(2):1768-1777

149. Huang $L$ et al (2018) Graphene-based nanomaterials for flexible and wearable supercapacitors. Small 14(43):1800879

150. Kakaei K, Esrafili MD, Ehsani A 2019 Graphene-based electrochemical supercapacitors. In: Interface science and technology. Elsevier, Amsterdam. pp 339-386

151. Härmas $M$ et al (2019) Hydrothermal and peat-derived carbons as electrode materials for high-efficient electrical double-layer capacitors. J Appl Electrochem 50:1-18

152. Wang JY et al (2019) Enhanced performance of electric double layer micro-supercapacitor based on novel carbon encapsulated $\mathrm{Cu}$ nanowire network structure as electrode. ACS Appl Mater Interfaces 11:40481

153. Horn M et al (2019) Graphene-based supercapacitor electrodes: addressing challenges in mechanisms and materials. Curr Opin Green Sustain Chem 17:42

154. Zhang $\mathrm{H}$ et al (2018) Graphene integrating carbon fiber and hierarchical porous carbon formed robust flexible "carbonconcrete" supercapacitor film. Carbon 126:500-506

155. Ehsani A, Heidari AA, Shiri HM (2019) Electrochemical pseudocapacitors based on ternary nanocomposite of conductive polymer/graphene/metal oxide: an introduction and review to it in recent studies. Chem Record 19(5):908-926

156. Hooch Antink W et al (2018) Recent progress in porous graphene and reduced graphene oxide-based nanomaterials for electrochemical energy storage devices. Adv Mater Interfaces 5(5):1701212

157. Wei F et al (2019) Synthesis of porous carbons from coal tar pitch for high-performance supercapacitors. New Carbon Mater 34(2):132-139

158. Xu C et al (2019) Controllable design of polypyrrole-iron oxide nanocoral architectures for supercapacitors with ultrahigh cycling stability. ACS Appl Energy Mater 2(3):2161-2168

159. Sun HB, Gu HZ, Chen $Y 2018$ Preparation and electrochemical properties of graphene/ $\mathrm{MnO}_{2}$ nanocomposites for supercapacitors. In: Key engineering materials. Trans Tech Publications

160. Haldorai $Y$ et al (2018) Metal-organic framework derived nanoporous carbon $/ \mathrm{CO}_{3} \mathrm{O}_{4}$ composite electrode as a sensing platform for the determination of glucose and high-performance supercapacitor. Carbon 127:366-373

161. Son Y-R, Park S-J (2019) Effect of graphene oxide/carbon nanotube ratio on electrochemical behaviors of spongy bone-like reduced graphene oxide/carbon nanotube foam prepared by simple and green approach. Chem Eng J 373:1020-1029

162. Lin J-H, Shi B-W, Chen Z-C (2018) High-performance asymmetric supercapacitors based on the surfactant/ionic liquid complex intercalated reduced graphene oxide composites. Applied Sciences 8(4):484

163. Mensing JP, Lomas T, Tuantranont A (2018) Ammonia strengthened graphene/CNT-wrapped polyaniline-nanofiber composites loaded with palladium nanoparticles for coin cell supercapacitors. Electrochim Acta 263:17-25

164. Yang $C$ et al (2019) Deriving $\mathrm{MoS}_{2}$ nanoribbons from their flakes by chemical vapor deposition. Nanotechnology 30(25):255602

165. Carbas BB, Tekin B (2018) Poly (3, 4-ethylenedioxythiophene) electrode grown in the presence of ionic liquid and its symmetrical electrochemical supercapacitor application. Polym Bull 75(4):1547-1562

166. Ma J et al. (2019) Conducting polymers based composite electrode materials in supercapacitor application. In: IOP conference series: earth and environmental science. 2019. IOP Publishing

167. Chen L, Wu L, Zhu J (2018) Carbon nanocomposites in electrochemical capacitor applications. Multifunc Nanocompos Energy Environ Appl 1:33-65

168. Zheng $M$ et al (2018) Hierarchically nanostructured transition metal oxides for supercapacitors. Sci China Mater 61(2):185-209

169. Muzaffar A, Muthusamy K, Basheer Ahamed M (2019) Ferrous nitrate-nickel oxide $\left(\mathrm{Fe}\left(\mathrm{NO}_{3}\right)\right.$ 2-NiO) nanospheres incorporated with carbon black and polyvinylidenefluoride for supercapacitor applications. J Electrochem Energy Convers Storage 16(3):031008

170. Xue F et al (2018) A three-dimensional graphene/CNT/ $\mathrm{MnO} 2$ hybrid as supercapacitor electrode. Integr Ferroelectr 190(1):156-163

171. Shah HU et al (2018) Hydrothermal synthesis of reduced graphene oxide- $\mathrm{Mn}_{3} \mathrm{O}_{4}$ nanocomposite as an efficient electrode materials for supercapacitors. Ceram Int 44(4):3580-3584

172. Xie $\mathrm{M}$ et al (2018) Facile growth of homogeneous $\mathrm{Ni}(\mathrm{OH})_{2}$ coating on carbon nanosheets for high-performance asymmetric supercapacitor applications. Nano Research 11(1):216-224

173. Gao H et al (2019) Two-phase interface-facilitated synthesis of graphene-like carbon nanosheets and their interfacial assembly behaviors. Chem Phys 516:132-138

174. García-Dalí S et al (2019) Aqueous cathodic exfoliation strategy toward solution-processable and phase-preserved $\mathrm{MoS}_{2}$ nanosheets for energy storage and catalytic applications. ACS Appl Mater Interfaces 11(40):36991-37003

175. Li K, Zhang J (2018) Recent advances in flexible supercapacitors based on carbon nanotubes and graphene. Sci China Mater 61(2):210-232

176. Li X et al (2018) High-sensitive humidity sensor based on graphene oxide with evenly dispersed multiwalled carbon nanotubes. Mater Chem Phys 207:135-140

177. Kumar S et al (2018) Optimized reduction of graphite oxide for highly exfoliated silver nanoparticles anchored graphene sheets for dye sensitized solar cell applications. Electrochim Acta 265:131-139

178. Xie J, Wang M (2018) High surface area nano-structured graphene composites and capacitive devices incorporating the same. Google Patents

179. Li $\mathrm{M}$ et al (2018) Embedding hollow $\mathrm{Co}_{3} \mathrm{O}_{4}$ nanoboxes into a three-dimensional macroporous graphene framework for high-performance energy storage devices. Nano Research 11(5):2836-2846

180. Jiang J, Watson TM, Wyatt PM (2019) Energy source devices and systems having a battery and an ultracapacitor. Google Patents

181. Huang $\mathrm{H}$ et al (2019) Facile fabrication of $\mathrm{MnO}_{2}$-embedded 3-Dporous polyaniline composite hydrogel for supercapacitor electrode with high loading. High Perform Polym. https://doi. org/10.1177/0954008319860893

182. Manjakkal L et al (2018) Flexible self-charging supercapacitor based on graphene-Ag-3D graphene foam electrodes. Nano Energy 51:604-612

183. Liao G et al (2018) Preparation, properties and applications of graphene-based hydrogels. Front Chem 6:450

184. Yu Z et al (2019) High energy density supercapacitor based on N/B co-doped graphene nanoarchitectures and ionic liquid electrolyte. lonics. https://doi.org/10.1007/s11581-019-02987 $-6$

185. Feng $\mathrm{H}$ et al (2019) Construction of 3D hierarchical porous $\mathrm{NiC02O4/graphene} \mathrm{hydrogel/Ni} \mathrm{foam} \mathrm{electrode} \mathrm{for} \mathrm{high-per-}$ formance supercapacitor. Electrochim Acta 299:116-124

186. Wen $J$ et al (2018) Novel high-performance asymmetric supercapacitors based on nickel-cobalt composite and PPy 
for flexible and wearable energy storage. J Power Sources 402:91-98

187. Hou M, Xu M, Li B (2018) Enhanced electrical conductivity of cellulose nanofiber/graphene composite paper with a sandwich structure. ACS Sustain Chem Eng 6(3):2983-2990

188. Nakajima $Y$ et al (2019) Low-temperature $\left(400^{\circ} \mathrm{C}\right)$ synthesis of multilayer graphene by metal-assisted sputtering deposition. ACS Omega 4(4):6677-6680

189. Pauzauskie PJ et al. (2018) Graphene aerogels. Google Patents

190. Zhou Y et al (2018) Engineering microsized materials through enhanced colloidal interactions of graphene for ultrahighmass-loading and flexible electrodes. ACS Appl Energy Mater 1(6):2378-2384

191. Mo L, Zheng H (2019) Growth of $\mathrm{MnO}_{2}$ nanoflakes on $\mathrm{TiO}_{2}$ nanorods for pseudocapacitor. J Alloy Compd 788:1162-1168

192. Hudak N, Schlichting A, Eisenbeiser K (2018) Enhanced structural supercapacitors. Google Patents

193. Hu Y (2018) Carbon and metal oxides based nanomaterials for flexible high performance asymmetric supercapacitors. Springer, Berlin

194. Wei C et al (2018) Synthesis of hierarchically porous $\mathrm{NiCO}_{2} \mathrm{~S}_{4}$ core-shell hollow spheres via self-template route for high performance supercapacitors. Appl Surf Sci 453:288-296

195. Xu K et al (2018) Hierarchical hollow $\mathrm{MnO}_{2}$ nanofibers with enhanced supercapacitor performance. J Colloid Interface Sci 513:448-454

196. Xu K et al (2019) Hierarchical assembly of manganese dioxide nanosheets on one-dimensional titanium nitride nanofibers for high-performance supercapacitors. J Coll Interface Sci 552:712

197. Liu XY et al (2019) Engineering hydrogenated manganese dioxide nanostructures for high-performance supercapacitors. J Colloid Interface Sci 537:661-670

198. Zhu $S$ et al (2018) Structural directed growth of ultrathin parallel birnessite on $\beta-\mathrm{MnO}_{2}$ for high-performance asymmetric supercapacitors. ACS Nano 12(2):1033-1042

199. Li X-X et al (2018) Hierarchical double-shelled poly (3, 4-ethylenedioxythiophene) and $\mathrm{MnO}_{2}$ decorated $\mathrm{Ni}$ nanotube arrays for durable and enhanced energy storage in supercapacitors. Electrochim Acta 264:46-52

200. Jeong J-H et al (2019) Electrodeposition of $\mathrm{a}-\mathrm{MnO}_{2} / \mathrm{Y}-\mathrm{MnO}_{2}$ on carbon nanotube for yarn supercapacitor. Sci Rep 9(1):1-8

201. Kumar R et al (2018) Porous indium oxide hollow spheres (PIOHS) for asymmetric electrochemical supercapacitor with excellent cycling stability. Electrochim Acta 270:87-95

202. Chan PY, Majid SR (2018) Synthesis and electrochemical characterization of amorphous manganese-nickel oxide as supercapacitor electrode material. lonics 24(2):539-548

203. Hasan $\mathrm{M}$ et al (2019) Low pressure chemical vapor deposition synthesis of large area hetero-doped mono-and few-layer graphene with nitrogen and oxygen species. Mater Res Express 6(5):055604
204. Comanescu F, Istrate A, Purica M (2018) Raman investigation of critical steps in monolayer graphene transfer form copper substrate to oxidized silicon by means of electrochemical delamination. In: 2018 International semiconductor conference (CAS). IEEE

205. Machon D et al (2018) Raman scattering studies of graphene under high pressure. J Raman Spectrosc 49(1):121-129

206. Kaur G et al (2019) Vibrational and thermodynamic properties of pure and gold adsorbed graphene. Vacuum 166:405

207. Laplanche $\mathrm{G}$ et al (2018) Elastic moduli and thermal expansion coefficients of medium-entropy subsystems of the CrMnFeCoNi high-entropy alloy. J Alloy Compd 746:244-255

208. Park B-J et al (2018) Defect-free graphene synthesized directly at $150 \mathrm{C}$ via chemical vapor deposition with no transfer. ACS Nano 12(2):2008-2016

209. Moreno-Bárcenas A et al (2018) Graphene synthesis using a CVD reactor and a discontinuous feed of gas precursor at atmospheric pressure. J Nanomater 2018:1

210. Tan Y et al. Raman spectroscopy of large-area graphene by wet transfer method. In: Fourth seminar on novel optoelectronic detection technology and application. International Society for Optics and Photonics

211. Pan Z-Z et al (2018) Microhoneycomb monoliths prepared by the unidirectional freeze-drying of cellulose nanofiber based sols: method and extensions. JoVE (J Vis Exp) 135:e57144

212. Orozco FAS et al (2019) Enhancing the energy spectrum of graphene quantum dot with external magnetic and AharonovBohm flux fields. Heliyon 5(8):e02224

213. Amigo $\mathrm{N}$ et al (2019) Effect of starch nanoparticles on the crystallization kinetics and photodegradation of high density polyethylene. Compos Part B Eng 174:106979

214. Ramezani M et al (2019) Graphene-based hybrid nanomaterials for biomedical applications. In: Biomedical applications of graphene and 2D nanomaterials. Elsevier, pp 119-141

215. Wang $X$ et al (2018) Non-covalently functionalized graphene strengthened poly (vinyl alcohol). Mater Des 139:372-379

216. Tiwari JK et al (2018) Graphene platelets reinforced aluminum matrix composite with enhanced strength by hot accumulative roll bonding. arXiv preprint arXiv: 1807.00198

217. Du X, Zhen K, Liu F (2018) Graphene reinforced magnesium matrix composites by hot pressed sintering. Digest J Nanomater Biostruct 13(3):827-833

218. Konakov V et al (2018) Synthesis, structure and mechanical properties of bulk "copper-graphene" composites. Rev Adv Mater Sci 57(2):151-157

Publisher's Note Springer Nature remains neutral with regard to jurisdictional claims in published maps and institutional affiliations. 